\title{
Sustentabilidad del turismo en el patrimonio minero: modelo conceptual e indicadores para el exterritorio carbonífero de Lota y Coronel
}

\author{
M. Isabel López. Universidad del Biobío, Concepción, Chile \\ Leonel Pérez. Universidad de Concepción, Concepción, Chile
}

RESUMEN | A partir de la década de los noventa, principalmente en Europa y Estados Unidos, surge desde el ámbito de la planificación urbana un creciente interés por la reutilización del patrimonio minero para usos culturales y turísticos. Quienes promueven este tipo de actuaciones destacan los aportes de dicho patrimonio a la dinamización de territorios en declive, a partir de la puesta en valor de los vestigios mineros y la introducción de nuevos usos basados en el turismo cultural. Sin embargo, aún existe una brecha en el desarrollo de metodologías capaces de medir la real contribución de este tipo de intervenciones al desarrollo local sustentable. En este contexto, el presente artículo propone una metodología de análisis derivada de la teoría de sistemas, y un sistema de indicadores que integra la perspectiva conservacionista y el desarrollo teórico de la sustentabilidad, y lo aplica al sistema de exasentamientos mineros del golfo de Arauco.

PALABRAS CLAVE | patrimonio, distritos industriales, sustentabilidad urbana.

ABSTRACT | Since 1990 onwards, various post mining sites of the XIX century have been turned into mining museums or parks, thus promoting industrial remains as touristic attractions. Advocators of this trend promote mining tourism as a way to revert economic and environmental decline. On the other hand, there is still a gap in methodological approaches aiming to assess the real contribution of these initiatives to sustainable local development. The article proposes an analytical method stemming out from systems' theory; and a set of indicators aiming to integrate principles of heritage preservation and sustainable tourism, and presents an application of the method in the analysis of the former coal mining territory of the Arauco Gulf, in Chile.

KEY WORDS | heritage, industrial districts, urban sustainability.

Recibido el 25 de octubre de 2011, aprobado el 24 de mayo de 2012

E-mail: M Isabel López,mlopez@ubiobio.cl | Leonel Pérez, leperez@udec.cl

Agradecimientos al Proyecto CYTED 412RT0444 y al Centro CONICYT/FONDAP 15110020, Centro de Desarrollo Urbano Sustentable. 


\section{Introducción}

Tarde o temprano el cierre de las minas constituye un evento inevitable, ya sea por la crisis de ciertos minerales específicos a partir del escenario posindustrial, o por el agotamiento natural de la veta. Es así como en la actualidad nos encontramos ante un panorama en el cual muchas ex comunidades mineras han experimentado como una catástrofe el fin de una forma de vida que -si bien era dura- constituía la base del orden económico y social aceptado durante generaciones.

Ante este escenario, desde la ingeniería de minas, diversos autores como Orche (2002a, 2002b, 2003 y 2004), Puche (2000 y 2003), Puche y Mazadiego (1993 y 1997), y Carvajal y González (2003a y 2003b) han valorado las trazas de la actividad minera como patrimonio cultural, y han promovido la reocupación de ex yacimientos o zonas de actividad metalúrgica para su visita por el público interesado. En consecuencia con ello, y fundamentalmente en Europa, organizaciones internacionales han impulsado la creación de museos, ecomuseos, museos de sitio, parques del territorio o parques culturales, con actividades turísticas, lúdicas, científicas o incluso terapéuticas (Sabaté, 2004; Carvajal y González (2003a), 2003; Orche, 2003; Sabaté \& Schuster, 2001).

Por otra parte, más allá de la argumentación más o menos favorable hacia estas actuaciones, se detectan dos deficiencias clave que deben ser abordadas. En primer lugar, una clarificación y delimitación conceptual de lo que implica este fenómeno como hecho territorial: ¿qué entenderemos por 'parque o museo minero'? Y en segundo lugar; ¿cuáles son sus aportes efectivos al desarrollo sustentable?

Como un avance en esta dirección, este trabajo esboza una propuesta metodológica que incluye tres perspectivas: descriptiva, evaluativa y prospectiva. La primera se orienta a caracterizar los principales componentes de las actuaciones y a construir una tipología -o taxonomía - de actuaciones sobre la base de ciertos aspectos diferenciadores. La perspectiva evaluativa intenta verificar las contribuciones de la actuación a la sustentabilidad. Finalmente, la perspectiva prospectiva explora el potencial que existe en un determinado ex territorio minero para implementar un turismo cultural sustentable. El enfoque descriptivo se apoya en la teoría de sistemas y en la herramienta del modelo conceptual; el evaluativo, en indicadores elaborados desde el marco teórico de la preservación y el turismo sustentable; y el prospectivo identifica atributos territoriales favorables para la sustentabilidad de las iniciativas.

La metodología ha sido desarrollada y aplicada en el contexto de actuaciones en el Reino Unido y en la ex zona carbonífera de Lota y Coronel. En los casos europeos, se aplicó el enfoque descriptivo y evaluativo. En el caso chileno, en cambio, dado lo incipiente del proceso de reconversión (López, 2010; Muñoz \& Sanhueza, 2006), se aplicó un enfoque prospectivo. Si bien el énfasis de este artículo es presentar la metodología, se describen algunos resultados que ejemplifican su utilidad, centrándose en el caso chileno. 


\section{Objeto de estudio, modelo conceptual e indicadores}

\subsection{Desde el campamento minero hasta el territorio patrimonial minero}

El concepto de campamento minero o company town ha sido caracterizado como una "forma menor y no necesariamente permanente de asentamiento, que incluye básicamente las funciones y construcciones relacionadas con la residencia: viviendas y equipamiento" (Garcés, Cooper \& Baros, 2007), en el que se permanece fuera del medio habitual en una relación intensa con el trabajo, y que actúa como satélite de una ciudad base. La condición de transitoriedad implica, al menos teóricamente, no solo la idea de montaje sino además, por extensión, la de desmontaje. Con un sentido más amplio, el concepto de territorio tiene virtudes evidentes para describir o adjetivar las transformaciones impulsadas por la actividad minera. La primera se refiere a su capacidad de aludir a diferentes escalas de análisis sin perder por ello precisión. La segunda es que evoca al mismo tiempo una realidad física y una realidad humana. Y la tercera es su transversalidad de uso y apropiación interdisciplinaria (Cáceres, 2001, p. 119). Finalmente, en relación con el territorio, el concepto que expresa la transformación de naturaleza en cultura es el de "paisaje cultural", término definido como el "resultado de la acción de un grupo social sobre un paisaje natural [donde la] cultura es el agente, lo natural es el medio y el paisaje cultural, el resultado" (Sauer, 2006 [1925]).

En síntesis, vemos que si el concepto de company town centra la mirada en el asentamiento minero, los conceptos de territorio y paisaje cultural constituyen un enfoque más inclusivo, que no solo incorpora la transformación de lo urbano; sino también aquellas que suceden en el ámbito geográfico (en el sistema de asentamientos, las redes e infraestructuras de comunicación marítima y terrestre, etcétera). Adicionalmente, como se explica más adelante, esta escala de análisis resulta particularmente apropiada para el caso específico del golfo de Arauco. ${ }^{1}$

\subsection{Referentes teóricos: sobre el concepto de modelo}

Spaulding (1953, p. 305, en Alcina, 1994, p. 83) define el concepto de "modelo" como un "grupo de artefactos que exhiben un consistente conjunto de atributos, cuyas propiedades combinadas proporcionan un patrón característico". Por otra parte, Watson, Le Blanc y Redman (1974, p. 140, en Alcina, 1994, p. 83) lo definen como "el resultado de dos o más atributos ligados entre sí por un vínculo no aleatorio". García Pelayo (1975; en Alcina, 1994, p. 85) señala que "el modelo debe ser más simple que la realidad, destacando lo más significativo de esta; debe ser asimismo más rico o más claro que la realidad, descubriendo la mayor parte de las relaciones subyacentes".

A partir de esta herramienta, se propone agrupar en categorías las variables que inciden en el fenómeno de la reutilización y organizarlas en un esquema

1 Al final del Apartado 2 
conceptual que llamaremos Modelo de Actuación. De esta manera se obtiene un patrón para la comparación de distintos casos de reutilización del exterritorio minero y la identificación de "tipos". De acuerdo con Hill y Evans (1972), el tipo es "un grupo que se ha formado sobre la base de un patrón de atributos de los materiales o hechos y que se distingue de otros tipos que tienen otros patrones de atributos" (p. 233). Aplicando esta definición al campo de estudio, es posible señalar que los tipos de reutilización del legado minero que se quiere identificar expresarán una combinación posible de los atributos definidos en el modelo. Mientras el modelo incluye todas las categorías de atributos (relevantes desde la perspectiva de análisis), el tipo solo identificará aquellas que resultan relevantes para cada caso específico.

En esta indagación se propone utilizar un modelo en el que la reutilización es conceptualizada como un sistema cuyas partes fundamentales son la actuación en sí, y el contexto en el que se sitúa.

La actuación comprende dos ámbitos: el espacio cultural minero en el que se despliega la reocupación, y una determinada estructura de administración y manejo. El espacio cultural minero involucra a su vez las variables de "sitio" y "programa". Por "sitio" entenderemos el área en la que se emplazan las actividades culturales y turísticas que reutilizan y ponen en valor el legado físico e intangible de la actividad minera. Por "programa" entenderemos las actividades culturales, educativas y turísticas que se despliegan (o podrían desplegarse) en el sitio patrimonial.

Por otra parte, el contexto involucra tanto una dimensión espacial o territorial como una dimensión social. Dentro del contexto espacial se consideró la presencia de otras grandes atracciones turísticas, las características del sistema de vías primarias y secundarias, así como la cercanía de las actuaciones respecto de los grandes centros poblados. Finalmente, dentro del contexto social se consideró las características del marco institucional y normativo de la ordenación de territorio a escala del país, así como el marco institucional y social de apoyo a la reutilización.

Desde una perspectiva descriptiva, el análisis del contexto social contribuye a caracterizar la actuación. Desde la perspectiva evaluativa, concurre a verificar el logro de metas de sustentabilidad social y económica. Y desde la perspectiva prospectiva, colabora en identificar los aspectos que favorecerían o dificultarían la implementación de la actuación. Este último enfoque se apoya en los descubrimientos que emanan del análisis descriptivo y evaluativo y en las vinculaciones que se deduce que existirían entre el diseño del modelo de gestión y el logro de ciertas metas de sustentabilidad.

\subsection{Referentes teóricos de los indicadores: aportes de la perspectiva conservacionista y del turismo sustentable}

La elaboración de los indicadores implicó, en primer lugar, definir ciertos principios y parámetros de rentabilidad que midiesen las actuaciones en términos tanto de resultado como de proceso. El análisis del proceso de reconversión implica 
construir una ordenación cronológica de las principales acciones o medidas implementadas desde el cese de la actividad extractiva, identificando aspectos como el sentido u objetivo de cada medida, los agentes que lideraron dichas acciones, el sector al cual pertenecían, y las principales estrategias o mecanismos utilizados en su implementación. El enfoque de proceso resulta extremadamente relevante, por cuanto permite analizar los cambios en un período (en las cifras de empleo, número de visitantes, etcétera) y, a partir de ahí, evaluar el impacto del proyecto sobre una determinada línea de base.

Aportes de la perspectiva conservacionista

Uno de los conceptos relevantes en el surgimiento del turismo cultural es el de "conservación integrada". Este concepto -surgido a fines de los años sesenta- implicó que los bienes patrimoniales pasaran a ser considerados factores de desarrollo territorial, y que la doctrina internacional abogara por su integración a los planes de desarrollo. La primera evidencia implícita del concepto de conservación integrada se produjo en las Normas de Quito de $1967^{2}$ (Cuadro 1), que señala que "los monumentos de interés arqueológico, histórico y artístico constituyen también recursos económicos" y "consecuentemente, las medidas conducentes a su preservación y adecuada utilización no solo guardan relación con los planes de desarrollo, sino que forman o deben formar parte de los mismos" ${ }^{3}$ (Hernández, 2003, p. 76). En este mismo sentido, la Resolución (68) XII del Comité de Ministros de $1968^{4}$ indica que la integración "es el medio más eficaz de garantizar su protección y rehabilitación (...), siendo la planificación a todos los niveles el medio más adecuado para alcanzar esta integración" (Hernández, 2003, p. 78). La crisis de fines de los setenta sumaría el interés de la doctrina por encontrar un valor económico a este nicho. Es así como diversas resoluciones europeas ratifican la visión del patrimonio cultural como factor de desarrollo territorial y la necesidad de integrar la conservación dentro de la planificación. ${ }^{5}$

Este punto de vista se consolida con la recuperación de las economías desarrolladas a fines de los ochenta. Posteriormente, a fines de los noventa, el octavo borrador de la Carta Internacional sobre Turismo Cultural (CITC) desarrolla aún más esta relación. Este borrador fue adoptado por el Icomos (International Council on Monuments and Sites/Consejo Internacional de Monumentos y Sitios) en octubre de $1999 .{ }^{6}$

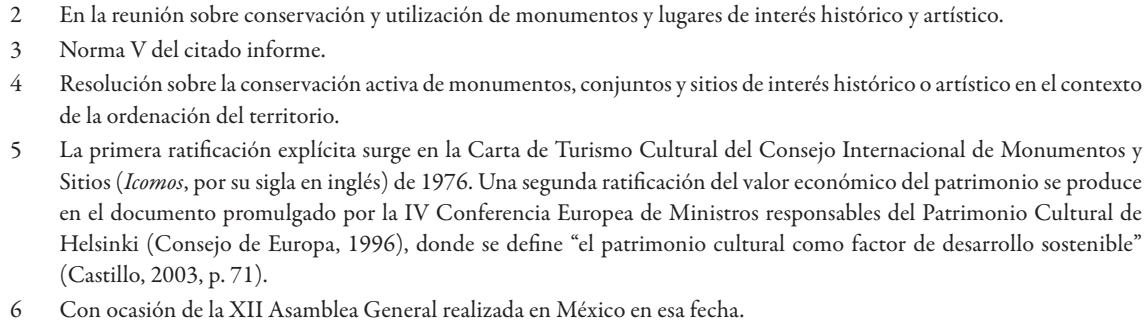


CUADRO 1 | Valoración económica del patrimonio en la doctrina internacional y europea

\begin{tabular}{|c|c|c|}
\hline CONFERENCIA & FECHA & Contenido \\
\hline \multicolumn{3}{|l|}{ Valoración económica implícita } \\
\hline \multirow[b]{2}{*}{ Normas de Quito. } & \multirow[b]{2}{*}{1967} & $\begin{array}{l}\text { 1. Se reconoce el valor económico de } \\
\text { los monumentos. }\end{array}$ \\
\hline & & $\begin{array}{l}\text { 2. Se promueve la integración de } \\
\text { medidas de preservación en los planes } \\
\text { desarrollo. }\end{array}$ \\
\hline $\begin{array}{l}\text { XII Comité de Ministros de Europa, } \\
\text { Resolución } 68 .\end{array}$ & 1968 & $\begin{array}{l}\text { Se reafirma la integración de medidas } \\
\text { de preservación del patrimonio en la } \\
\text { planificación en todos los niveles. }\end{array}$ \\
\hline \multicolumn{3}{|c|}{ Ratifica la integración de la preservación en los planes de desarrollo } \\
\hline $\begin{array}{l}\text { Primera Conferencia Europea de Minis- } \\
\text { tros Responsables de la Salvaguarda y } \\
\text { Rehabilitación del Patrimonio Cultural } \\
\text { Inmobiliario (Resolución } N^{\circ} 1 \text { ). }\end{array}$ & 1969 & $\begin{array}{l}\text { Ratifica la integración de medidas } \\
\text { de preservación a la planificación en } \\
\text { todos los niveles. }\end{array}$ \\
\hline $\begin{array}{l}\text { Carta Europea del Patrimonio Arqui- } \\
\text { tectónico de Ámsterdam en Consejo de } \\
\text { Ministros de Europa. }\end{array}$ & 1975 & $\begin{array}{l}\text { Se utiliza por primera vez el apelativo } \\
\text { "conservación integrada". }\end{array}$ \\
\hline \multicolumn{3}{|l|}{ Valoración económica explícita } \\
\hline Carta de Turismo Cultural del Iсомоs. & 1976 & $\begin{array}{l}\text { La valoración del patrimonio como } \\
\text { factor de desarrollo se hace más } \\
\text { evidente. }\end{array}$ \\
\hline $\begin{array}{l}\text { IV Conferencia Europea de Ministros } \\
\text { responsables del Patrimonio Cultural de } \\
\text { Helsinki; Consejo de Europa. }\end{array}$ & 1996 & $\begin{array}{l}\text { Se desarrolla la vinculación entre } \\
\text { patrimonio y desarrollo. }\end{array}$ \\
\hline $\begin{array}{l}\text { Octavo borrador de la Carta Internacio- } \\
\text { nal sobre Turismo Cultural, Icomos. }\end{array}$ & 1999 & $\begin{array}{l}\text { Se desarrolla la vinculación entre } \\
\text { patrimonio y desarrollo. }\end{array}$ \\
\hline
\end{tabular}

FUENTE ELABORACIÓN PROPIA.

En Latinoamérica, en 1999 se redacta la Declaratoria y Conclusiones del Primer Congreso Latinoamericano sobre Conservación, Identidad y Desarrollo, "Reflexiones hacia el nuevo milenio", en el que los participantes se comprometen a "propiciar la generación de modelos alternativos de conservación del patrimonio, que apoyen a las comunidades en la recreación de sus tradiciones y en la búsqueda de nuevos significados ante el futuro". En conclusión, el concepto de turismo cultural emerge estrechamente vinculado a la apreciación del potencial económico del patrimonio y a la integración de las acciones de conservación en los planes de desarrollo territorial.

7 Realizado en el Museo Nacional de Antropología, Ciudad de México, del 17 al 19 de noviembre. 
Principios del turismo cultural

A partir de la CITC y el informe de la Unesco (Hernández, 2003), se identifican los siguientes principios fundamentales del turismo cultural. En primer lugar, que su objetivo fundamental es educativo. Este principio pone de relieve la importancia de la interpretación del patrimonio como mecanismo que permite, tanto a la comunidad anfitriona como a los visitantes, comprender el significado del patrimonio y validarlo en el tiempo; y paralelamente, comprender la cultura que lo sustenta. Un segundo principio apunta al papel del turismo cultural como estrategia para financiar los fines educativos y de conservación, y como contribución al desarrollo económico. Un tercer principio es que la explotación turística debe respetar los valores (paisajísticos y culturales) de las diferentes comunidades y grupos sociales involucrados. Esto apunta a prevenir las consecuencias del turismo excesivo y a la necesidad de fijar límites a su explotación. Un cuarto principio es que la gestión del turismo cultural debería contar con el compromiso y la cooperación de los representantes locales. Así se asegura la sostenibilidad del turismo y la protección de los recursos patrimoniales para futuras generaciones. En consonancia con este enfoque, Hernández (2003) plantea la necesidad de reemplazar el modelo de gestión tradicional o "ilustrado", por otro basado en una intensa participación de todos los actores sociales (p.75). Finalmente, el quinto principio plantea que el principal beneficiario de la gestión turística del patrimonio debe ser la comunidad anfitriona. Este principio enfatiza el rol de los legisladores para asegurar una distribución equitativa de los recursos obtenidos.

\section{Aportes desde la perspectiva del turismo sustentable}

El concepto de turismo sustentable ha sido definido como aquel que "responde a las necesidades de los turistas actuales y las regiones receptivas, protegiendo y agrandando las oportunidades del futuro. Se le representa como el rector de todos los recursos, de modo que las necesidades económicas, sociales y estéticas puedan ser satisfechas manteniendo la integridad cultural, los procesos ecológicos esenciales, la diversidad biológica y los sistemas en defensa de la vida" (World Tourism Organization [WTO], 1993, p. 23). Hunter (2002, pp. 1-3, en Cole, 2004, p. 481) sugiere dos principios para garantizar la compatibilidad entre turismo y sustentabilidad: protección medioambiental, y vinculación entre crecimiento económico y bienestar. A este mismo respecto, Sharpley (2000, p. 8, en Cole, 2004, p. 481) identifica tres principios: primero, una aproximación holística a la planificación del desarrollo; segundo, tener la continuidad en el largo plazo o "futurismo"; y tercero, asegurar la equidad en la selección de desarrollos que beneficien a toda la sociedad, ahora y en el futuro.

Similarmente, los principios de turismo sostenible sintetizados por Fariña ${ }^{9}$ a partir de la Organización Mundial del Turismo (OMT) y el English Tourist Board (ETB) señalan:

Referido al excesivo protagonismo del Estado.

9 José Fariña, “Turismo Sostenible”, apunte docente del Doctorado en Desarrollo Urbano Sostenible del Departamento de Urbanística y Ordenación del Territorio, Escuela Técnica Superior de Arquitectura de Madrid (ETSAM), Universidad Politécnica de Madrid, España. Véase punto 1.8. 
- que el valor intrínseco del medioambiente es superior al valor del turismo;

- que los límites de la explotación turística comienzan cuando se afecta la integridad del medioambiente y de la comunidad local;

- que tanto gobiernos locales como organismos del medioambiente son responsables de velar porque la industria turística respete los principios $-\mathrm{y}$ límites- de un turismo sostenible.

Estrechamente relacionado con los límites de la explotación turística surge el concepto de "capacidad de carga", definido por la Organización Mundial del Turismo como el "número máximo de personas que pueden visitar a la vez un lugar turístico, sin dañar el medio físico, económico o sociocultural, y sin reducir de manera apreciable la calidad de la experiencia de los visitantes". ${ }^{10}$

\subsection{Parámetros e indicadores de sostenibilidad del turismo de patrimonio minero}

A partir de los referentes analizados, para evaluar la sustentabilidad del turismo de patrimonio minero en Lota y Coronel se proponen parámetros de sustentabilidad social, de sustentabilidad ambiental y de sustentabilidad económica.

\section{Parámetros de sustentabilidad social}

Un primer parámetro de sustentabilidad social es que la comunidad local tenga un rol preponderante en la gestión turística del patrimonio minero. Esto apunta a analizar si el modelo de gestión implementado considera la participación de una amplia gama de actores sociales interesados en el proyecto de reconversión; y, especialmente, la participación de los actores locales. Se parte de la premisa de que la participación activa de la comunidad local favorece la autenticidad de la interpretación, así como una distribución de los beneficios económicos que priorice la protección del recurso patrimonial y el desarrollo de la comunidad. La participación puede ser evaluada mediante de la asignación de roles en el proyecto de puesta en valor, así como en su estructura de administración y manejo. $\mathrm{Al}$ respecto, se debe considerar: el reconocimiento de un rol relevante a los distintos actores sociales en la gestión del patrimonio; la distribución de la propiedad del legado patrimonial entre potenciales actores (locales o foráneos, públicos o privados, etcétera); y la existencia o no de directorios, corporaciones de desarrollo u otros que conformen mesas de negociación y expresión de instancias locales en el proyecto turístico.

Un segundo parámetro de sustentabilidad social se refiere a que el proyecto valorice la cultura minera local. Se propone analizar si la intervención ha favorecido la comprensión de la cultura minera, incluyendo no solo los vestigios físicos de la actividad minero-metalúrgica, sino la valorización integral del legado como expresión de la cultura local. Indicadores para medir este aspecto pueden ser las diferentes acciones consideradas en el proyecto, que deberían incluir actividades como:

- registro de aspectos de la organización social e institucional y de las creencias y culturas compartidas de las comunidades mineras; por

10 Punto 2.1 de Fariña, "Turismo Sostenible". 
ejemplo, por la promoción de la investigación, creación de centros de documentación, impulso a las publicaciones, etcétera;

- acciones de interpretación del patrimonio cultural que reflejen la historia local coincidiendo con la perspectiva local;

- implementación de medios de presentación y difusión de manera relevante y accesible para la comunidad anfitriona y el visitante, que proporcionen información histórica, cultural y del entorno físico; por ejemplo, en museos o centros de interpretación, organización de seminarios, cursos u otras actividades artístico/culturales, folletos de difusión u otras publicaciones, etcétera.

\section{Parámetros de sustentabilidad ambiental}

Dos ámbitos deben ser evaluados respecto de la sustentabilidad ambiental del turismo patrimonial minero. En primer lugar, su contribución a la rehabilitación ambiental de los exyacimientos mineros y a la mitigación del riesgo ambiental derivado de factores naturales y antrópicos, relacionados con la actividad extractiva. Se considerarían como indicadores de este parámetro las acciones y mecanismos implementados o planificados, y la inclusión, en el proceso de planificación y gestión del proyecto, de agentes que velen por el cumplimiento de estos objetivos.

En segundo lugar, debe evaluarse la conservación de las trazas de la actividad minera como elementos importantes de la identidad del lugar. Este principio toma partido en la polémica entre quienes se manifiestan a favor de eliminar todas las trazas de la actividad extractiva, y quienes destacan la importancia del patrimonio minero para la historia local (Cole, 2004; Jonsen-Verbeke, 1999, p. 74; y Leary \& Sholes, 2000, p. 52). Se utilizarían como indicadores de este parámetro: las acciones de conservación y recuperación del paisaje minero, la existencia de mecanismos de protección del paisaje, y la de mecanismos que permitan destinar los recursos que se obtengan de la explotación turística a la recuperación del paisaje.

\section{Parámetros de sustentabilidad económica}

En términos de la sustentabilidad económica, se propone considerar los siguientes parámetros. Primero, que el proyecto de parque minero esté integrado a planes más amplios y holísticos de desarrollo, que permitan potenciarlo con otras atracciones y revertir problemas como la falta de capacitación y asistencia financiera a la comunidad local. Segundo, que sea beneficioso económicamente a escala local, comprobable en términos de aumento en la inversión, descenso en los índices de desempleo y aumento en el número de visitantes al año. Tercero, que el principal beneficiario de la actividad turística sea la comunidad anfitriona. Un indicador para medir este último aspecto es la existencia de un marco legal, o instrumentos de planificación, que aseguren una distribución equitativa de los recursos y beneficios. ${ }^{11}$ 


\section{El exterritorio carbonífero de Lota y Coronel}

La minería del carbón se desarrolló en Chile fundamentalmente en tres áreas del sur: el golfo de Arauco en la Región del Biobío (Mazzei, 1997); cerca de las ciudades de Valdivia y Chiloé en las regiones de Los Ríos y Los Lagos; y en la cuenca de Magallanes, en la región del mismo nombre (Martinic, 2004 y 2010). Sin embargo, existe consenso en cuanto a que fue el golfo de Arauco la zona que lideró la producción carbonífera en Chile y a cuyo nivel de producción no se le acercaba ninguna otra (Ortega, 1992). En el golfo de Arauco se destacaron las labores iniciadas el año 1850 por Matías Cousiño en la bahía de Lota, Federico Schwager en la bahía de Coronel, y Matías Rioseco en Lebu (Pizarro, 1991). De estos yacimientos, el más destacado fue el desarrollado en Lota y, en segundo lugar, en Coronel; por lo tanto, para el análisis se consideró un área de estudio que incluía las zonas patrimoniales de ambas ciudades (Figura 1).

FIGURA 1 | Área de estudio en Lota y Coronel

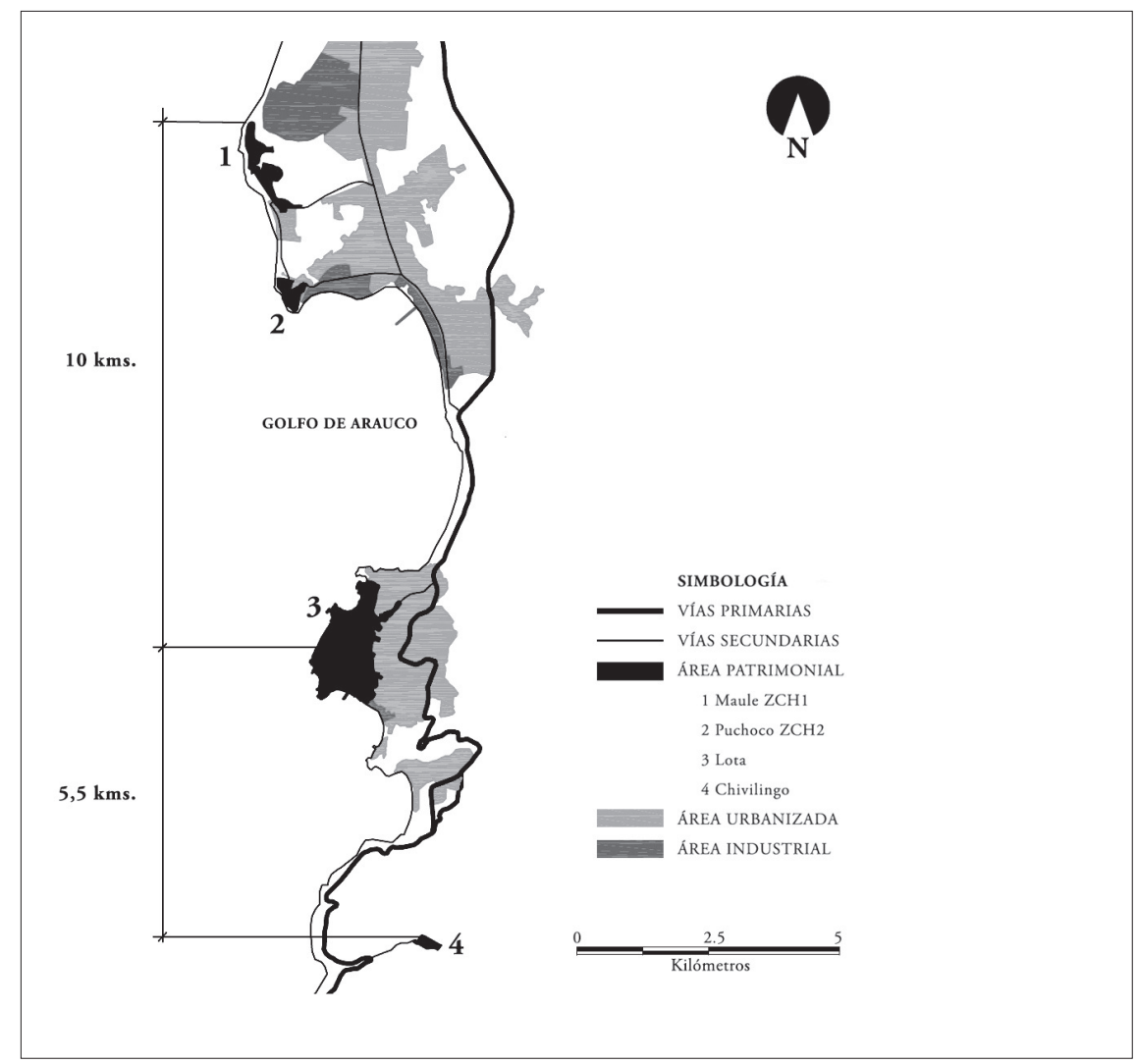

FUENTE ELABORACIÓN PROPIA. 
Los paisajes culturales asociados a la minería constituyen una de las expresiones más representativas del patrimonio industrial chileno. Desde la Colonia, pero con especial intensidad en el siglo XIX, la minería es el origen de paisajes culturales de particular significación, como los poblados del salitre, del cobre y del carbón. Para su comprensión, son de vital importancia los estudios de Garcés (1999) sobre las ciudades del salitre del Norte Grande y de Garcés, Cooper y Baros (2007) para los campamentos mineros del cobre, así como los trabajos de Muñoz y Sanhueza $(2006)^{12}$ sobre Lota, y de Pérez (2008a) sobre Puchoco, en Coronel. Todos ellos cubren grandes vacíos de conocimiento sobre estos paisajes culturales creados por la minería.

Según Ortega (1992), Lota y Coronel, además de estar entre los complejos industriales más grandes del país a fines del siglo XIX, fueron poblados profundamente modificados por la instauración de nuevas formas de vida, y la construcción de instalaciones industriales, edificios de equipamiento, viviendas y espacios públicos que, hasta hoy, definen el carácter de los barrios, constituyen hitos fundamentales del paisaje urbano y son elementos clave de la estructura urbana.

En Lota, el campamento minero de Lota Alto se desarrolló relacionando la industria con la vivienda, siguiendo una estructura social jerárquica similar a la organización laboral de la industria (Muñoz, 2000). Desde este origen, el campamento evolucionó para adaptarse a las particulares condiciones de relieve del territorio, característica que explica sus rasgos urbanísticos singulares. El crecimiento del campamento fue planificado por la empresa, al tiempo que se planificaba la expansión del complejo minero. Los barrios crecían a la par de la industria, y la incorporación de nuevas tecnologías para mejorar los procesos industriales también se aplicaba al desarrollo urbano del campamento (Figura 2).

La actividad desarrollada en Coronel desde mediados del siglo XIX tuvo como enclave principal el sector de Puchoco, en el que se instaló el complejo industrialminero en el extremo norte de la bahía (Aburto \& Gutiérrez, 1999, p. 43). Este lugar se constituyó en punto de atracción de capitales y mano de obra. El poblamiento de Schwager recibió gran impulso en 1872 con la prolongación de la línea de ferrocarriles hacia el sur del río Biobío (Vera, 1984, pp. 13-14). Si bien el asentamiento se originó a causa del proceso de industrialización provocado por la extracción carbonífera en Punta Puchoco y Boca Maule, no fue sino hasta 1892 cuando se unieron ambos poblados, ${ }^{13}$ produciéndose una de las transformaciones y cambios territoriales, sociales, urbanos y económicos más importantes de la región del Biobío (Figura 3).

12 El texto citado es resultado de una investigación Fondecyt desarrollada en torno a los tres ejes de identidad, memoria colectiva y participación, y tuvo como principal valor o innovación la aplicación de una metodología participativa para la identificación, evaluación y jerarquización del patrimonio arquitectónico y urbano.

13 Los complejos industriales de Puchoco-Délano y Puchoco-Schwager, "conjuntamente a los establecimientos de Boca Maule y Huerta, constituyeron la Compañía Carbonífera y de Fundición Schwager, que fue autorizada por decreto supremo fechado el 27 de mayo de 1892" (Aburto \& Gutiérrez, 1999-2000, p. 7). 
FIGURA 2 | Edificios patrimoniales en Lota Alto

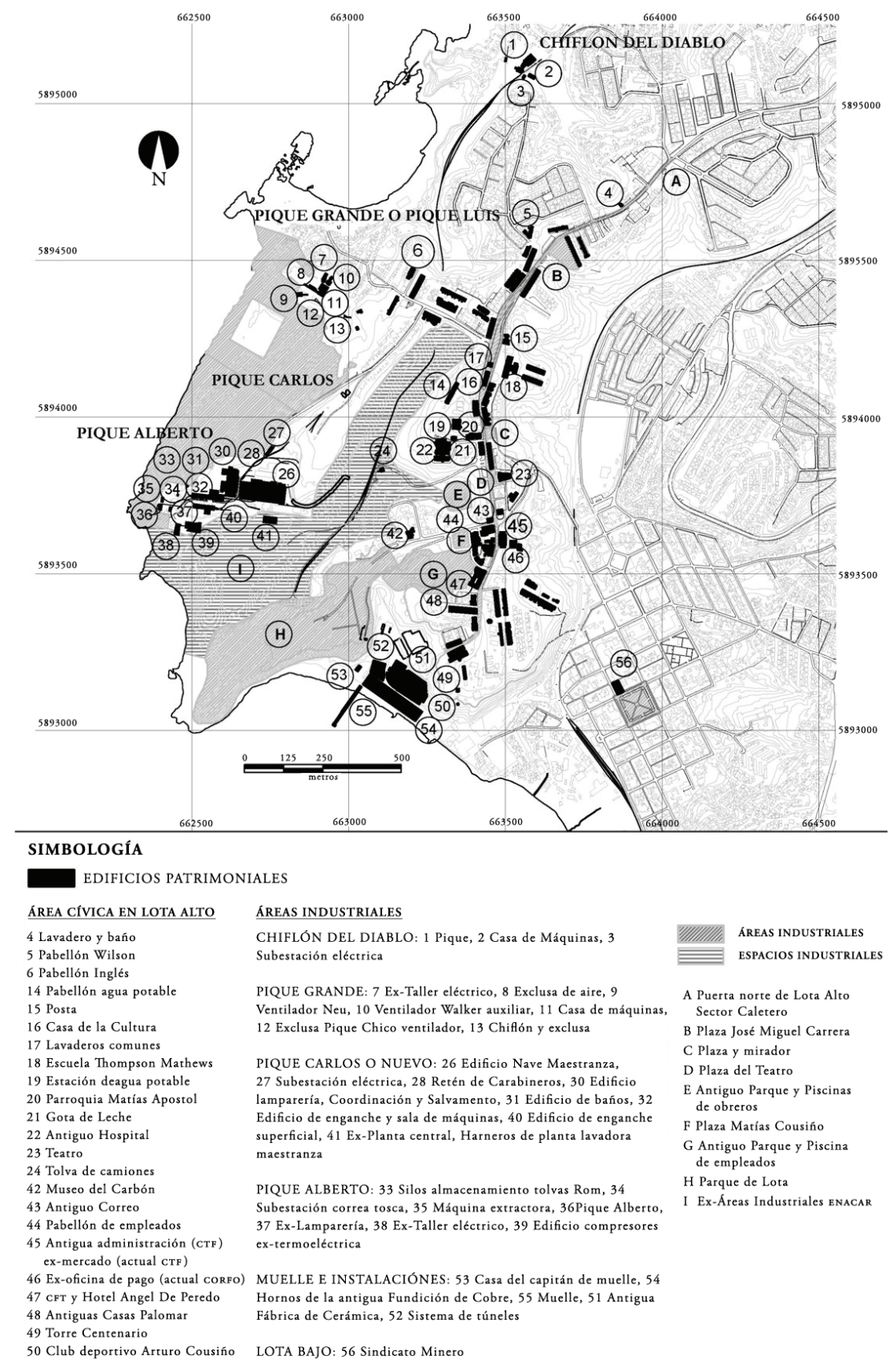

FUENTE ELABORACIÓN PROPIA. 
FIgURa 3 | Edificios patrimoniales en Maule y Puchoco

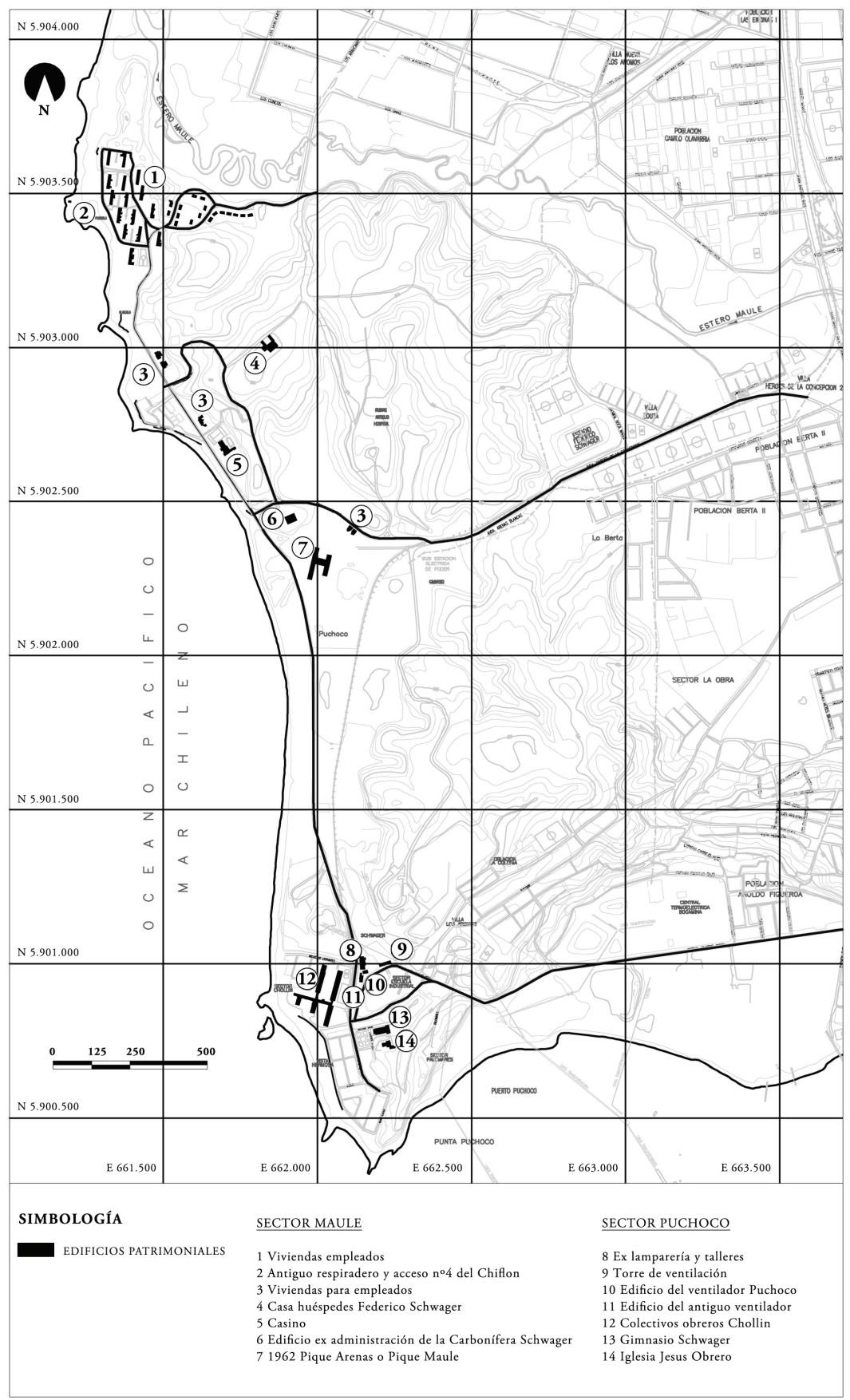

FUENTE ELABORACIÓN PROPIA. 
La minería del carbón definió y potenció el desarrollo de Lota y Coronel. Sin embargo, las particulares condiciones de producción del carbón, los métodos de trabajo, la infraestructura técnica y el precio del producto respecto de los costes, llevaron al agravamiento particularizado de una prolongada crisis, que culminó con el cierre de las minas de Puchoco en 1994, y de Lota en 1997 (Pérez, Muñoz \& Sanhueza, 2004).

Uno de los aspectos más significativos del patrimonio minero industrial en Lota y Coronel reside en su importancia como impulso a la penetración de la zona "salvaje" ubicada al sur del Biobío y su incorporación a la naciente República. Hitos en este proceso fueron la construcción del primer puente ferroviario (el más largo de la época) sobre el río Biobío; la penetración del ferrocarril y la construcción de los puertos; la modificación de amplias zonas de paisajes; y la expansión de uno de los complejos minero-industriales más grandes de la época en Chile y el continente sudamericano, cuyas propiedades en la región superaban por mucho, en superficie, la suma total de las propiedades salitreras distribuidas en dos regiones y en alrededor de 170 oficinas (López, 2010, p. 389).

Así, parece particularmente apropiado abordar estos asentamientos -y en adelante nos referiremos a ellos en estos términos- como territorio o paisaje cultural, conceptos que transmiten la complejidad y la profundidad del impacto industrial, tanto en la dimensión física como social de dichas comunidades.

\subsection{Aplicación del modelo al caso chileno}

A continuación se presentan los principales resultados de la aplicación del modelo, los parámetros e indicadores al exterritorio carbonífero de Lota y Coronel. Como se señala en la introducción, se aplica en este caso un enfoque prospectivo, orientado a identificar el potencial del territorio -a la vez que los desafíos- para un turismo sostenible del patrimonio minero.

\section{El sitio de la actuación}

Dependiendo del tipo de actuación, podemos distinguir al menos tres formas para definir los límites de un determinado sitio de manejo: i) a partir de los límites de propiedad, cuando ellos coinciden con los límites del área patrimonial minera que se propone reutilizar; ii) a partir de un instrumento de planificación local vinculante, forma utilizada, por ejemplo, cuando el límite del sitio coincide con los límites de una determinada Área de Conservación Histórica; y iii) a partir de un instrumento de planificación no vinculante, local o intercomunal cuando, por ejemplo, los límites del sitio son definidos por un plan de manejo. Este es el caso de la exárea minero-industrial de Ironbridge Gorge, donde los límites del sitio coinciden con el área designada por la Unesco como Patrimonio de la Humanidad (Figura 4). 
FIGURA 4 | Límites del sitio patrimonial de Ironbridge Gorge

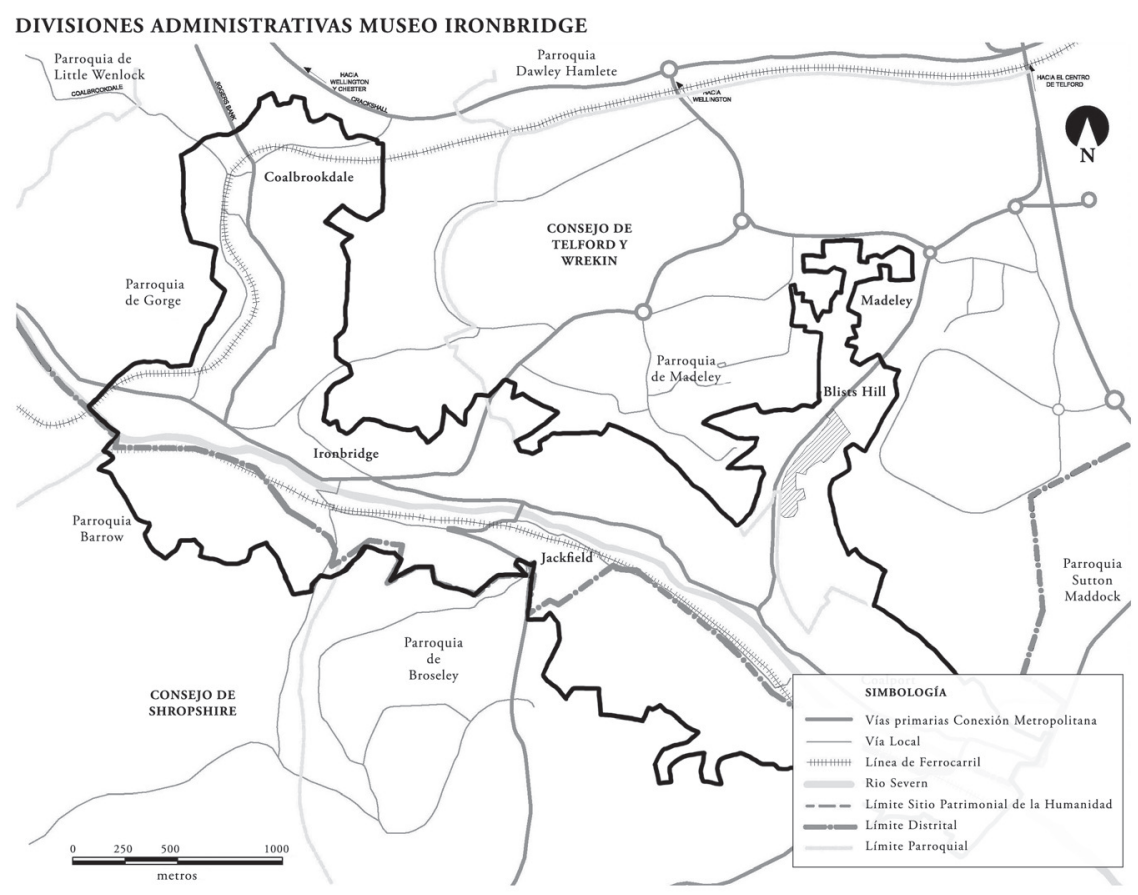

FUENTE ELABORACIÓN PROPIA, A PARTIR DE WWW.IRONBRIDGE.ORG.UK/ABOUT_US/WORLD_HERITAGE_SITE.

En Lota y Coronel podemos diferenciar al menos tres posibles límites de un área de manejo. Bajo un primer criterio - más acotado- podrían incluirse las siguientes áreas:

- Las zonas de conservación históricas de Maule y Puchoco definidas en el nuevo Plan Regulador de Coronel. ${ }^{14} \mathrm{El}$ barrio Maule fue lugar de residencia de los empleados de mayor jerarquía de la compañía, adquiriendo con ello el estatus de barrio acomodado. El conjunto Puchoco-Maule llegó a conformar una ciudadela con un conjunto de servicios que lo hacían prácticamente independiente de Coronel.

- La zona de conservación histórica (ZCH) de Lota Alto, delimitada en el estudio Surplan Ltda., y Eliash (2005) en torno a la avenida Cousiño. En esta zona se concentra el mayor número de sitios e inmuebles patrimoniales, como los Monumentos Nacionales Pabellón 83, Teatro de Lota, Parque Isidora Cousiño y Chiflón del Diablo (Figura 5, 6, 7, 8 y 9). Una variante menos restringida es la que propone el Plan Regulador de Lota, en elaboración, que incluye la exzona mineroindustrial, en al que se destacan los piques Luis o Grande, Carlos y Alberto.

14 Actualmente en proceso de aprobación. 
FIguras 5 y 6 | Vistas de diversos tramos de la avenida Carlos Cousiño en Lota: el Pabellón 51 y la Casa de la Cultura, excomedor y lugar de reunión de las familias mineras

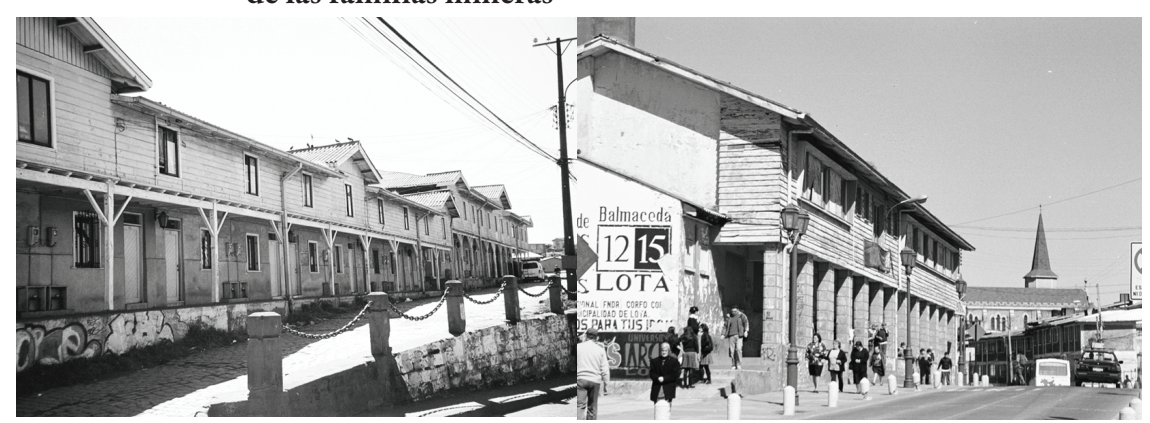

FUENTE SURPLAN (2005)

FIGURAS 7 Y 8 | Vista de la iglesia Matías Apóstol por medio del corredor del Pabellón 22, y el Pabellón 83, hoy rehabilitado como Centro Cultural

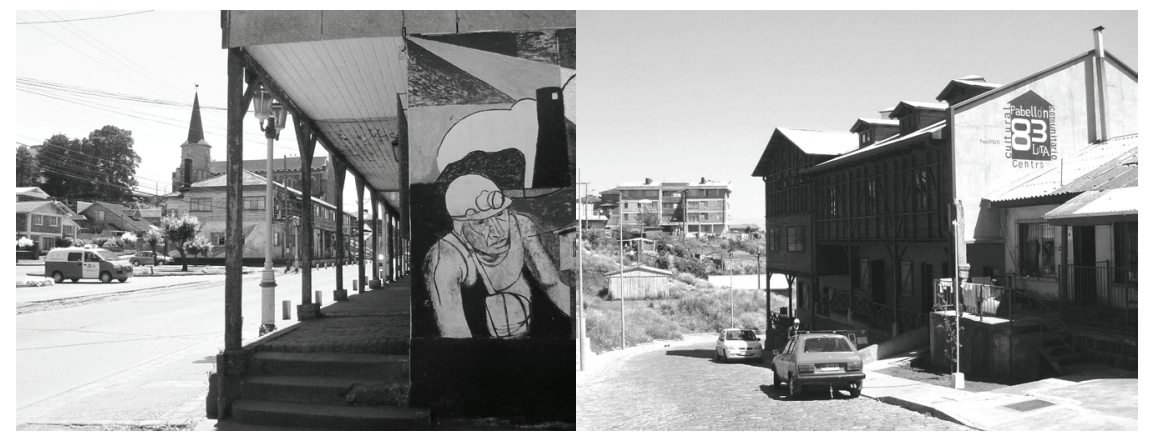

FUENTE COLECCIÓN PROPIA.

FIGURA 9 | Teatro de Lota

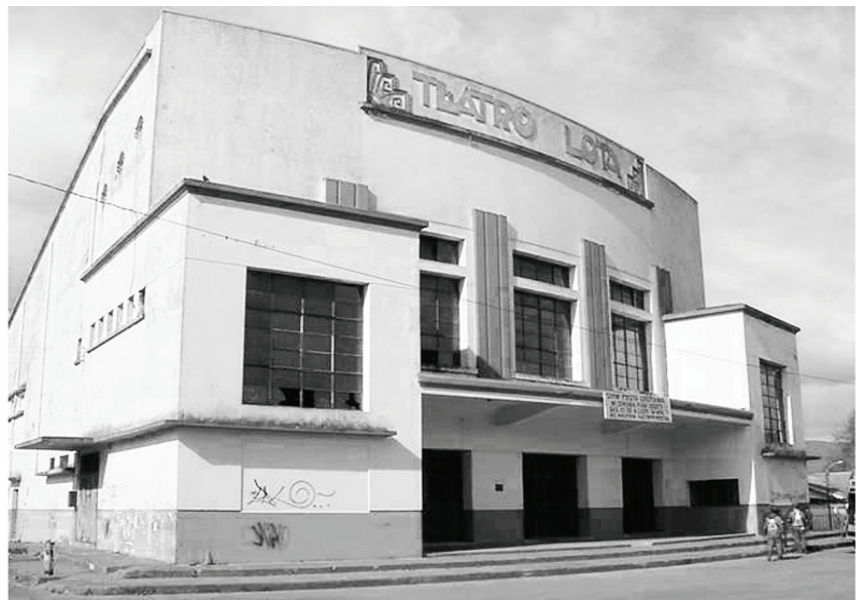

FUENTE SURPLAN (2005). 
Una segunda posibilidad -muy defendida por diversos actores de la comunidad local en Lota- es promover un área de manejo que incorpore más integralmente las zonas de Lota Bajo y Lota Alto. Los promotores de esta opción argumentan la significancia de los inmuebles patrimoniales ubicados alrededor de la plaza, como la sede del sindicato obrero y el espacio de la feria de Lota, entre otros.

Finalmente, una tercera opción es incluir el área de manejo no solo el patrimonio construido, sino también el paisaje minero, en consideración al marcado arraigo geográfico de la excomunidad minera con la llamada "zona del carbón”. Un poderoso argumento para sostener la significancia patrimonial del paisaje minero es la intensa ocupación del territorio en actividades colectivas. Al respecto señalan Aravena y Betancur (1995), en relación a Lota, que "algunos lugares propios (...) como el mar, la playa o los bosques fueron el contexto necesario y "facilitador" para que se formara una determinada estructura social y económica en la comuna"; de tal manera que en estos espacios la comunidad construyó "su historia, sus patrones y estrategias de vida" (punto 1.4, p. 26).

El programa

El programa cultural y turístico podría incluir los siguientes tipos de elementos:

a. Atractivos turísticos de patrimonio cultural desarrollados a partir de la reutilización de las exinstalaciones mineras e industriales, y de los edificios de equipamiento ubicados en los exasentamientos mineros; estos pueden incluir usos como galerías subterráneas abiertas al público, museos temáticos que muestren aspectos del trabajo minero, museos científicos interactivos, etcétera.

b. Atractivos turísticos de paisaje natural y/o paisaje minero, desarrollados a partir de la recuperación de espacios exteriores de valor patrimonial, como parques, plazas u otros; o del acondicionamiento de bosques, o áreas naturales significativas por el uso y el significado que tuvieron en la época minera. $\mathrm{El}$ acondicionamiento puede incluir elementos como senderos y paseos que "cuenten" la manera en que estos espacios eran usados en la época minera (como lugares de fiestas colectivas, procesiones, etcétera) o contribuyan a apreciar las señas de la actividad minera en el paisaje local.

c. Infraestructura cultural, educativa y científica, incluyendo espacios como lugares de espectáculos y ferias de artesanía, hasta bibliotecas, centros de documentación y archivos, y centros de enseñanza superior donde se impartan carreras como geología, historia, restauración, etcétera, o carreras para las cuales el área patrimonial sea un laboratorio vivo.

d. Infraestructura turística, incluyendo centros de información, estacionamientos, lugares de oferta gastronómica y alojamiento, entre otros; estos últimos pueden reutilizar diferentes instalaciones y equipamientos de la época minera. Por ejemplo, expabellones de mineros acondicionados como lugares de alojamiento para estudiantes o turistas, etcétera. 
En Lota es posible identificar iniciativas turísticas y culturales que -de manera disgregada y desconectada - se acercan a esta propuesta. Una de las más importantes ha sido la implementación del Circuito Turístico Lota Sorprendente. ${ }^{15}$ Administrado hasta el año 2011 por la Fundación Chile, mediante la figura del comodato cedido por la Corporación de Fomento de la Producción (Corfo), ${ }^{16}$ incluía los sitios patrimoniales del Chiflón de Diablo, parque Isidora Cousiño, la ex-Casa de la Administración del Parque (reocupada como Museo Histórico Minero) y la Central Hidroeléctrica de Chivilingo.

Por otra parte, una de las principales deficiencias ha sido la excesiva focalización de este tipo de iniciativas en Lota Alto; falta una visión más sistémica y unitaria de la comuna que incluya Lota Alto y Bajo y los recursos paisajísticos del borde costero, así como una estrategia global que integre las áreas patrimoniales de la comuna de Coronel.

La estructura de administración y manejo

Finalmente, por "estructura de administración y manejo" entenderemos la organización que permite gestionar la actuación, el o los actores que participan en ella, el tipo de funciones que cumple cada uno y los mecanismos e instrumentos que regulan la manera en que se relacionan entre sí. El diseño de la estructura de manejo es un aspecto clave para la sustentabilidad social de la actuación.

El sitio de manejo podría incluir tanto áreas minero-industriales abandonadas como exasentamientos mineros habitados. Por lo tanto, la estructura de administración debiese considerar mecanismos para incorporar y comprometer con la iniciativa no solo a los grandes propietarios de los sitios (por ejemplo, las antiguas compañías mineras), sino también a representantes de intereses específicos de la comunidad local, como unidades vecinales, dueños de negocios, operadores turísticos, ambientalistas, preservacionistas, etcétera, así como a los gobiernos locales con jurisdicción en el sitio patrimonial.

El análisis de la estructura de manejo debería incluir la individualización de las escalas de planificación que están representadas (por ejemplo, local y supralocal), así como la identificación del sector (público, privado o "alianza" público-privada) a la que pertenecen las entidades participantes. Además, deben considerarse los mecanismos necesarios para incluir la opinión de la comunidad local en extenso (por ejemplo, mediante encuestas).

El análisis sugiere que la estructura de administración y manejo del área patrimonial minera en Lota y Coronel debería manifestarse en dos escalas de planificación del territorio: local y supralocal.

En la escala local, donde la Ley Orgánica de Municipalidades lo permite, se propone la creación de una Corporación Cultural o fundación sin fines de lucro, constituida por los gobiernos locales y organizaciones sociales representativas de la comunidad (sindicales, vecinales y organizaciones no gubernamentales, ONG). Se entiende esta

15 Otra es el museo minero de Puchoco a partir de la reocupación del antiguo chiflón, que depende de una corporación vinculada a la Municipalidad de Coronel.

16 A partir del 16 de enero de 2012, transferido a la Corporación Baldomero Lillo. 
Corporación como una entidad de derecho privado cuya misión central sería la recuperación, preservación y administración de los sitios e inmuebles patrimoniales más significativos. Para que esto fuese posible, se requiere traspasar la propiedad -o, en su defecto, los derechos de administración- a la Corporación. ${ }^{17}$ La misma figura debería repetirse para efectos de recuperar y conservar sitios de patrimonio paisajístico.

La figura de la Corporación Cultural se introduce de manera que los gobiernos locales puedan asociarse entre sí y con las organizaciones sociales locales para la administración del recurso patrimonial. Y adicionalmente, como un mecanismo que les permite una mayor flexibilidad de gestión, por ejemplo para contratar personal calificado, sin las restricciones que impone la normativa de la administración pública en Chile. ${ }^{18}$

En la escala supralocal se propone que estas corporaciones se incorporen a una mesa de trabajo interagencias, en la que también participen otras entidades públicas y privadas del nivel local y central. En Lota y Coronel, estas incluyen a los municipios respectivos; a los servicios y agencias públicas sectoriales más relevantes para la reutilización del área; ${ }^{19} \mathrm{y}$ a otras organizaciones sindicales, vecinales y gremiales (vinculadas con el turismo, el arte, la cultura y el deporte, entre otras).

Mientras que en la escala local la función principal de las corporaciones de patrimonio cultural y natural sería administrar las propiedades a su cargo, la mesa inter-agencias tendría las siguientes funciones: articular entre sí las distintas iniciativas que se desarrollen dentro del área patrimonial, mediante un plan de manejo; y velar porque las inversiones y decisiones de desarrollo sectorial que sean tomadas en la escala supralocal sean consistentes con los objetivos del plan de manejo.

\section{El contexto territorial}

Por contexto territorial entenderemos las siguientes variables: distancia del exterritorio minero que se quiere reutilizar, con respecto de los grandes centros poblados; características de la red de vías primarias y secundarias; y número de habitantes en el entorno próximo a los sitios mineros.

Se propone limitar este análisis a las áreas más próximas al sitio patrimonial minero, sobre la base de que diversos estudios (Cole, 2004, p. 485; y Hospers, 2002, p. 401) señalan que este tipo de atracciones apela fundamentalmente a visitantes diurnos. Esto queda reafirmado a partir de los tiempos sugeridos de visita de diversos sitios de turismo de patrimonio minero, que fluctúan entre las tres horas y un día. ${ }^{20} \mathrm{~A}$ partir de este dato, resulta lógico presumir que el factor de cercanía es un aspecto relevante en términos de facilitar o desincentivar la visita. De ahí que se propone definir un área de estudio delimitada por las siguientes variables:

17 Desde la Corfo y los municipios locales, que son sus actuales propietarios.

18 En el caso de los municipios, esta normativa está definida fundamentalmente por la Ley Orgánica Constitucional de Municipalidades.

19 Por ejemplo, el Ministerio de Obras Públicas (MOP); el Ministerio de Vivienda y Urbanismo (Minvu) y su ente ejecutor, el Servicio de Vivienda y Urbanización (Serviu); el Consejo Nacional de la Cultura y las Artes (CNCA), entre otros.

20 www.ironbridgegorge.org, y otros. 
- Un isócrono centrado en el sitio minero; cuyo radio -dependiendo de las condiciones de cada territorio (densidad poblacional, accesibilidad geográfica, patrones de movilidad, etcétera) - podría fluctuar entre los 20 y los 40 kilómetros.

- La distancia a la que se encuentre el área urbana de gran población más cercana. El número de habitantes involucrados en el concepto "gran población" dependerá también de lo que se entienda en cada país por ello.

El análisis de casos en el Reino Unido sugiere algunas características territoriales que favorecen el logro de ciertos parámetros de sustentabilidad. En primer lugar, que se cumpla una relación inversamente proporcional entre la escala del sitio y su cercanía respecto de los grandes centros urbanos. De esta manera, una ubicación relativamente alejada (que demanda mayor tiempo de viaje) es compensada por la expectativa de encontrar un área turística más extensa. Como referencia, cuatro de los seis museos mineros más visitados se localizan en áreas urbanas, suburbanas o a menos de una hora de viaje, desde grandes conglomerados urbanos, siendo los museos mineros más alejados los de Ironbridge Gorge y Beamish Museum, que presentan áreas significativamente más extensas que el resto ${ }^{21}$ (Figura 10 y Cuadro 2).

FIGURA 10 | Escala de cuatro de los museos mineros más visitados en el Reino Unido y ubicación respecto de áreas urbanas

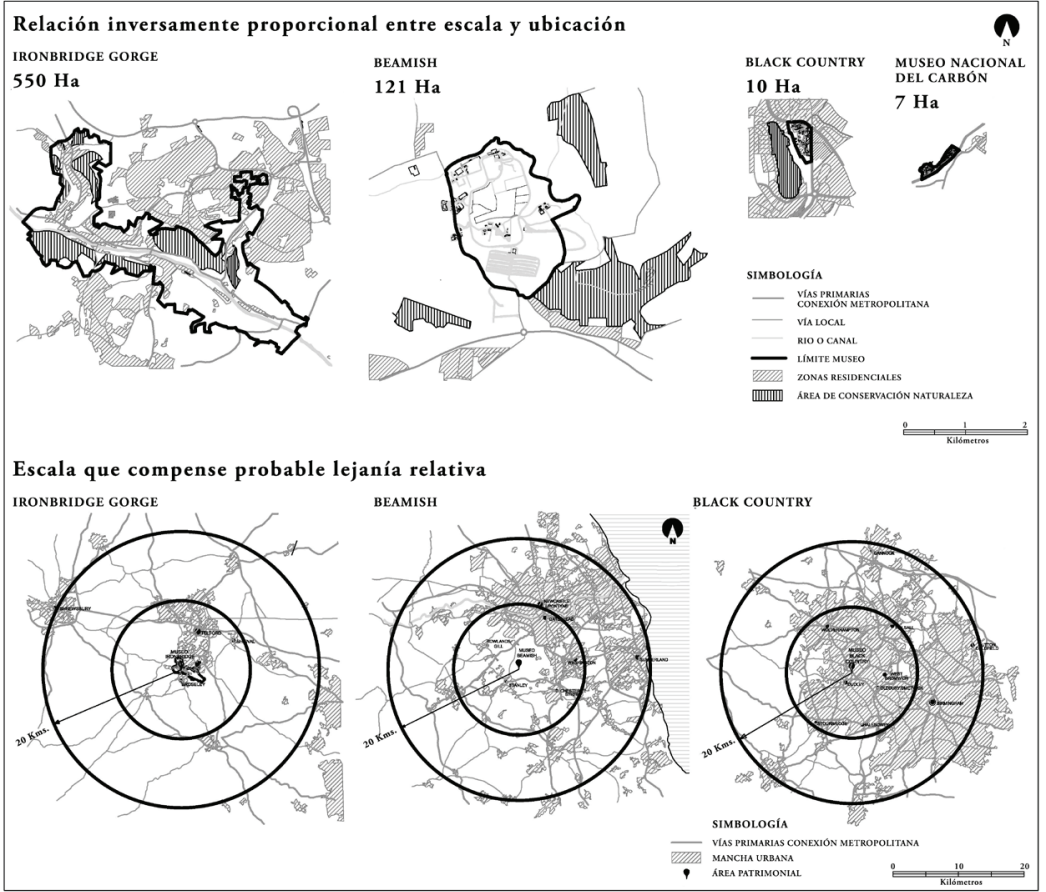

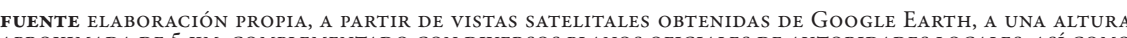
APROXIMADA DE 5 KM, COMPLEMENTADO CON DIVERSOS PLANOS OFICIALES DE AUTORIDADES LOCALES, ASÍ COMO

21 El sitio patrimonial minero de Ironbridge Gorge, que solo tiene alrededor de 200.000 habitantes en su entorno próximo, se ubica a 45 minutos de la conurbación metropolitana del West Midlands, que tiene más de 2 millones de habitantes (de acuerdo con Censo 2001, Key Statistics for Urban Áreas). 
Otro atributo relevante es que el área patrimonial minera esté integrada a un territorio "vivo", atributo que constituye un impulso para que la actuación sea incluida en planes más holísticos de desarrollo local, así como para la construcción de formas más participativas de manejo. Adicionalmente, contribuye a lograr una comprensión más cabal de la cultura local por parte de los visitantes. Como se detallará, el primer aspecto contribuye a la rentabilidad económica de la actuación, y los dos últimos, a su rentabilidad social.

CUADRO 2 | Escala de los sitios mineros y relación respecto de áreas urbanas del entorno próximo

\begin{tabular}{|l|c|c|c|c|}
\hline \multirow{2}{*}{} & \multicolumn{2}{|c|}{ SITIO MINERo } & $\begin{array}{c}\text { NÚMERO DE HABI- } \\
\text { TANTES EN ENTORNO } \\
\text { PRÓXIMO }\end{array}$ & \multirow{2}{*}{ UBICACIÓN } \\
\cline { 2 - 5 } & Superficie (ha) & Escala $^{(2)}$ & $\begin{array}{c}\text { (millones de habi- } \\
\text { tantes) }\end{array}$ & \\
\hline BCM & 10 & comunal & 2 & urbana \\
\hline NCM & 6 & comunal & 1 & suburbana \\
\hline Beamish & 125 & regional & 1 & suburbana \\
\hline Ironbridge & 550 & suprarregional & 0,2 & semirrural \\
\hline
\end{tabular}

FUENTE ELABORACIÓN PROPIA

Notas:

(1) A MENOS DE 20 KM DEL MUSEO MiNERO.

(2) Según taxonomía propuesta por López (2010, p. 68).

$\mathrm{Al}$ analizar el área patrimonial minera de Lota y Coronel se constata que ella presenta atributos territoriales favorables para un turismo patrimonial minero.

En cuanto a la escala del potencial sitio de manejo (Figura 1), el área patrimonial de Lota y Coronel puede ser entendida como un borde costero en el que se van enlazando tres "estaciones" patrimoniales: Maule y Puchoco en Coronel, Lota Alto en Lota, y la Central Hidroeléctrica de Chivilingo en esta misma comuna. Las áreas patrimoniales de Maule y Puchoco abarcan una superficie aproximada de 64 hectáreas; las de Lota Alto, 198 hectáreas; y la de Chivilingo, alrededor de 7 hectáreas más; de esta manera, la suma de las tres "estaciones" alcanza una superficie total de alrededor de 262 hectáreas; es decir, de acuerdo con la taxonomía propuesta por López (2010), una escala regional.

En cuanto a la relación entre patrimonio minero construido y áreas pobladas, se observa que las áreas patrimoniales de Maule, Puchoco y Lota Alto están estrechamente vinculadas y superpuestas al sistema de asentamientos de Coronel y Lota, así como al sistema de vías primarias, secundarias y locales (Figuras 10 y 11); es decir, que cumple con el atributo de ser un territorio "vivo".

Finalmente, en cuanto a la cercanía respecto de un conglomerado urbano de gran población, vemos que Lota y Coronel forman parte del "sistema de centros urbanos integrados" del Área Metropolitana de Concepción, la que tiene una población de más de 900.000 habitantes. Lota, la ciudad más alejada, se encuentra a 36,5 km de Concepción (Figura 13). Por otra parte, junto con esta situación favorable, debe considerarse 
su ubicación periférica en la estructura tentacular que caracteriza a este sistema territorial. Si bien el área patrimonial minera tiene buena accesibilidad desde la Ruta 160, que es una vía expresa, aún está pendiente mejorar los medios de transporte público. Una medida en este sentido es el proyecto BioVías, para dotar al área de los servicios de tren urbano. Otra medida muy demandada por Lota y que abarataría los costos del desplazamiento en automóvil y del transporte público, es el traslado del peaje desde su ubicación actual, antes de Lota, hasta después de la comuna.

FIGURA 11 | Relación entre área patrimonial minera y áreas habitadas en Lota Alto

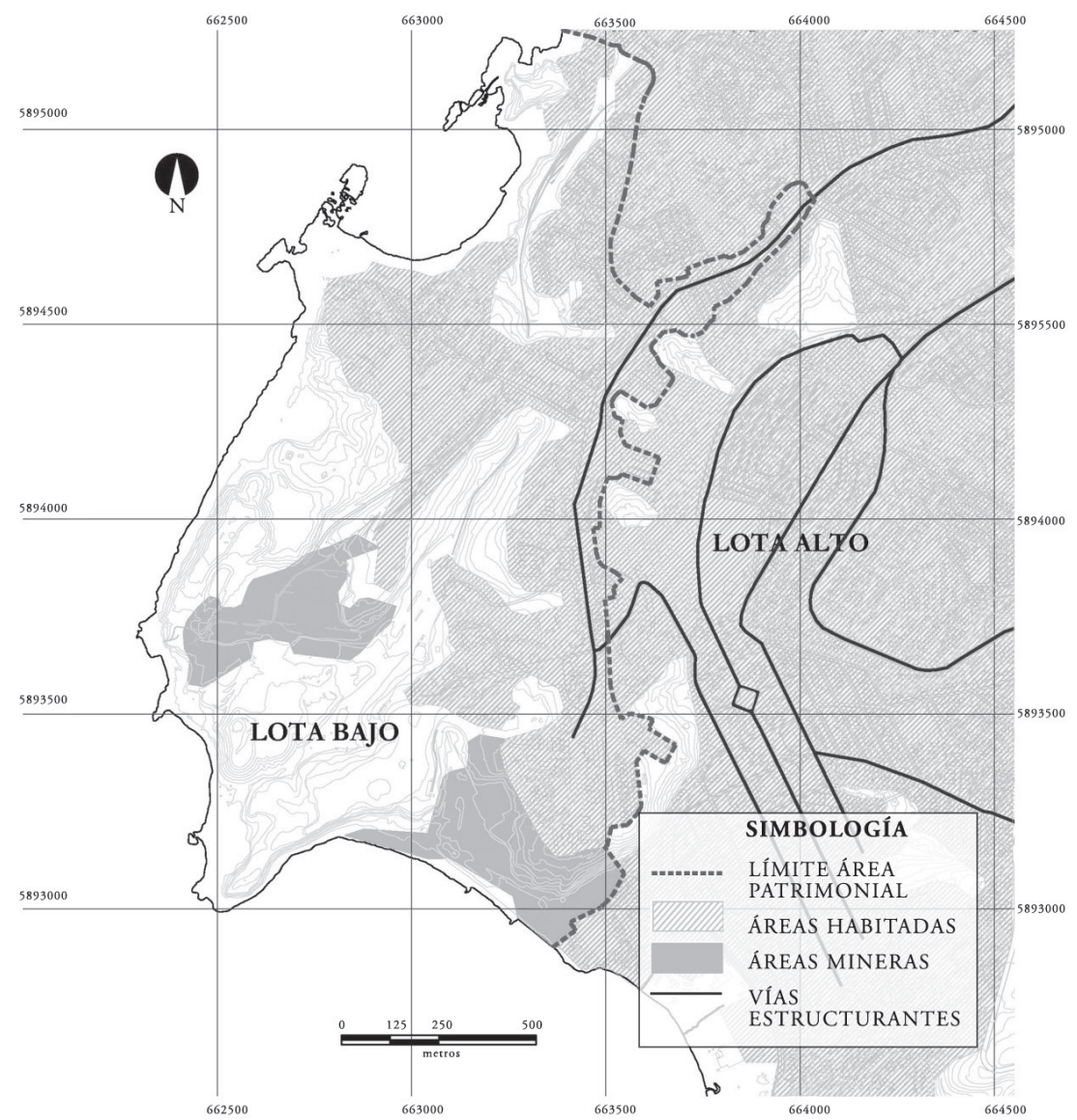

FUENTE ELABORACIÓN PROPIA. 
FIGURA 12 | Relación entre área patrimonial minera y áreas habitadas en Maule y Puchoco

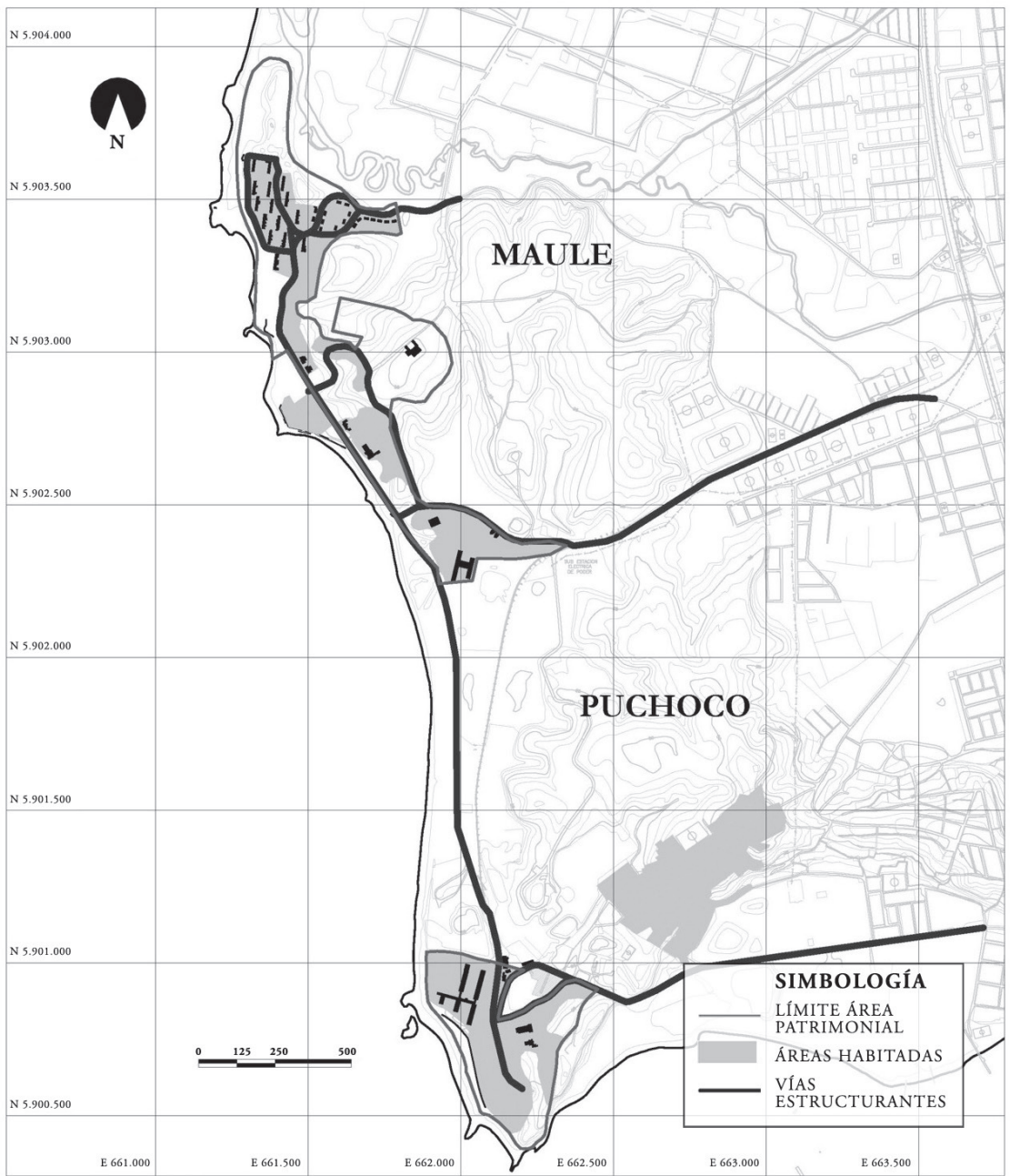

FUENTE ELABORACIÓN PROPIA. 
FIgURA 13 | Ubicación de Lota y Coronel respecto del Área Metropolitana de Concepción

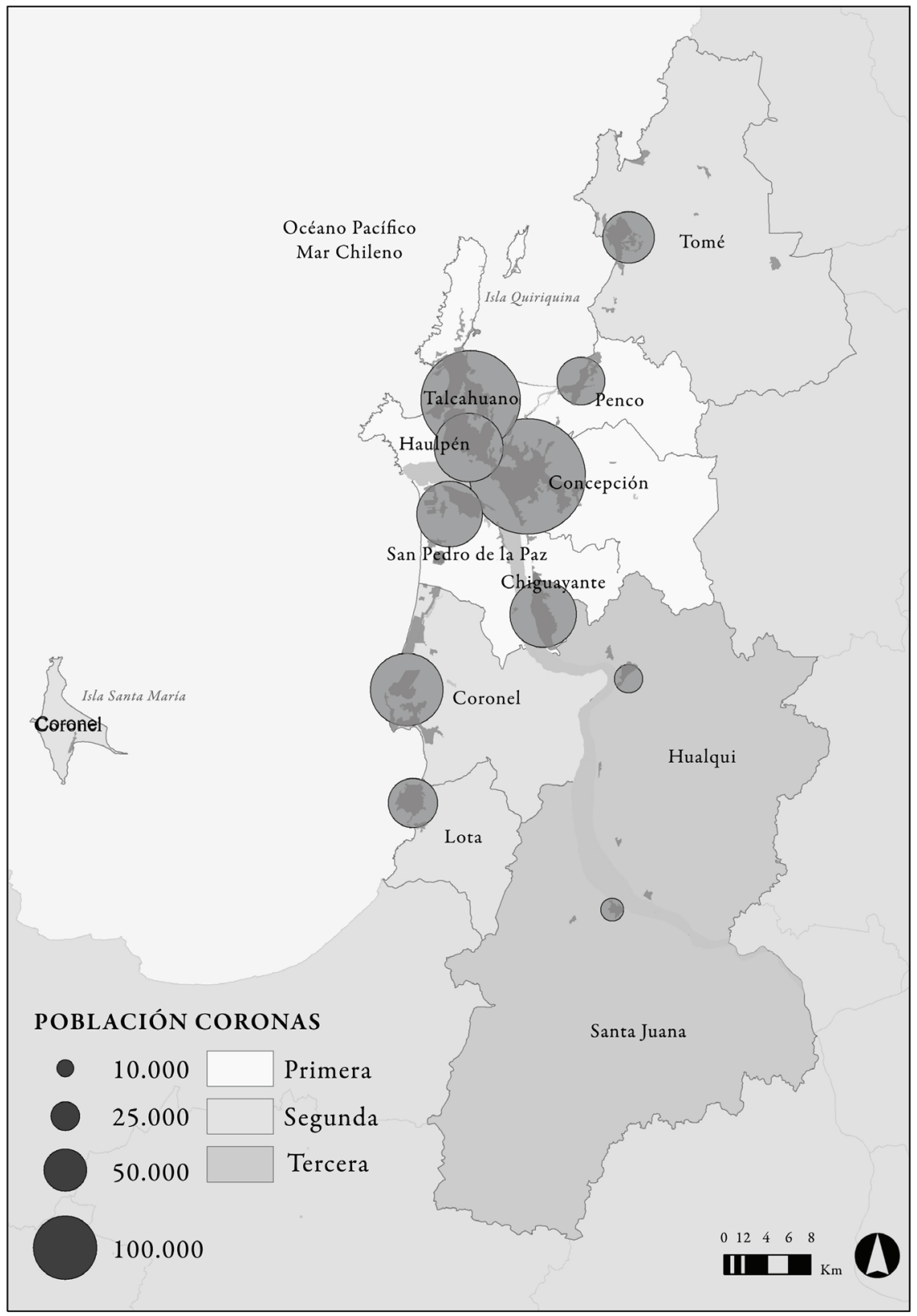

FUENTE Rojas (2009). 


\section{El contexto social}

En el caso chileno, el análisis revela importantes debilidades en el marco normativo e institucional del desarrollo urbano y la preservación del patrimonio, que sería necesario resolver para impulsar este tipo de actuaciones. Una de las escasas fortalezas es la existencia de una política favorable para abordar los desequilibrios territoriales desde el nivel regional. Esto se ha traducido, en la Región del Biobío, en la focalización de políticas de desarrollo y de inversión pública en el exterritorio minero de Lota y Coronel, definido como Territorio de Reconversión. Ello permite -en la escala regional- asignar recursos públicos para la reactivación de exterritorios mineros en declive. En relación con la preservación del patrimonio, otra fortaleza es el compromiso explícito, declarado en el marco legislativo del Estado, respecto de la preservación y difusión del patrimonio cultural, el que se visualiza desde una perspectiva amplia (incluyendo sus dimensiones tangible e intangible) y vinculado al tema de la identidad de los pueblos, y de la cultura en general. Finalmente, la tercera fortaleza se refiere a las atribuciones que les otorga la Ley Orgánica Constitucional de Municipalidades a los gobiernos locales para la recuperación y hasta cierto punto para la gestión del patrimonio. Es así como los gobiernos comunales son los principales responsables de desarrollar y aplicar los instrumentos de protección del patrimonio. Y teóricamente podrían, mediante de su participación en corporaciones de desarrollo cultural y asociaciones entre municipalidades, ampliar dichas facultades para la recuperación e incluso la administración del patrimonio.

Por otra parte, una de las principales debilidades en Chile en materia patrimonial es la falta de una política nacional de desarrollo urbano, que sería fundamental para levantar en la agenda nacional el caso de enclaves territoriales específicos en declive, como las exzonas mineras e industriales.

En segundo lugar, y como contrapartida a la fortaleza mencionada en el primer párrafo, han disminuido la eficacia de la planificación en los niveles regional e intercomunal (o metropolitano) factores como el carácter sectorial de la entidad a cargo de impulsar el cumplimiento de los instrumentos de planificación urbana (el Ministerio de Vivienda y Urbanismo); la superposición y dispersión de facultades y responsabilidades en el ámbito del desarrollo urbano, sumado a la falta de instancias eficaces de coordinación intersectorial; y el carácter no vinculante de los instrumentos de planificación regional.

En el ámbito local, los principales problemas detectados se refieren a la excesiva centralidad en la toma de decisiones, así como a la falta de mecanismos que fortalezcan y controlen la eficacia de las instancias de trabajo asociativo público-privado. El análisis del proceso de reconversión implementado hasta la fecha en Lota y Coronel muestra evidencias de que esta carencia ha afectado la eficacia y el potencial alcance de las mesas de trabajo público-privadas en el ámbito de la recuperación y puesta en valor del patrimonio (López, 2010).

Finalmente, se observan debilidades para incorporar la reutilización del exterritorio minero a una estrategia integral de regeneración urbana. Esta fragilidad puede deberse a la relativa inexperiencia del Estado chileno en proyectos urbanos público- 
privados de gran escala, ${ }^{22}$ así como al relativamente breve tiempo transcurrido desde las primeras actuaciones de este tipo. ${ }^{23}$

Existen otras limitaciones específicas del marco de la preservación del patrimonio en Chile. Primero, que los instrumentos existentes se centran en la protección del patrimonio (frente al riesgo de demolición o alteración), en desmedro de acciones más proactivas para la recuperación y, sobre todo, la gestión del recurso patrimonial. Esto contrasta con la situación en el Reino Unido, donde la praxis y el marco legislativo incorporan los planes de manejo y los planes de acción asociados, como los instrumentos que necesariamente deben complementar los instrumentos estatutarios de protección del legado patrimonial y natural.

A lo anterior puede agregarse la falta de una entidad que se ocupe integralmente de la preservación del patrimonio. En lugar de ello, se constata la existencia de una diversidad de entidades -escasamente coordinadas entre sí- que abordan este tema de manera tangencial o parcial (Figura 14). Adicionalmente, se observa una desvinculación entre estos entes del nivel nacional y las instituciones encargadas del ordenamiento territorial.

Un tercer problema se refiere a la falta de un fondo a escala nacional para estos fines. Como compensación, existen ciertas líneas de financiamiento en diversos servicios. Por otra parte, dichas líneas privilegian iniciativas lideradas por entidades del Estado y para bienes de su propiedad, en desmedro del financiamiento a proyectos que pudieran ser liderados por entidades de la sociedad civil o privados. O tienen sesgos (como el caso del Ministerio de Vivienda y Urbanismo respecto de la vivienda social) inherentes a los fines sectoriales o específicos de cada servicio. Aparentemente esta limitación no sería tan relevante en el caso de Lota y Coronel, donde la mayoría de los inmuebles aún son propiedad del Estado. ${ }^{24}$ Sin embargo, ha tenido impacto en la falta de mantención y reparación de los inmuebles de equipamiento e industriales vendidos a privados. Si bien las ONG tienen la opción de buscar el patrocinio de alguna entidad pública (municipios, gobierno regional, u otros), en definitiva su autonomía se ve disminuida.

Finalmente, una última debilidad se refiere a la aún escasa participación de la sociedad civil en la preservación del patrimonio. Esto sugiere que una política nacional de impulso a la preservación podría orientarse hacia el fortalecimiento de las capacidades y recursos de estas organizaciones.

22 Tanto en términos del número como la escala de las iniciativas.

23 Otras debilidades generales del desarrollo urbano en Chile se derivan de: i) Los extensos plazos que requiere el sistema nacional de inversiones públicas (SNI), los que les restan agilidad a este tipo de proyectos; ii) El estilo centralizado y sectorial de los servicios, que dificulta la coordinación entre agentes del Estado y quita agilidad a la toma de decisiones; iii) La falta de mecanismos más formales de participación ciudadana en las iniciativas de proyectos urbanos integrales, y la aún débil participación de los gobiernos locales; iv) La restricción de las facultades del ente usualmente a cargo de implementar dichos proyectos (el Servicio de Vivienda y Urbanización, Serviu), problema que impide aprovechar al máximo sus capacidades como corporación de desarrollo urbano. Esto contrasta con los poderes de las corporaciones de desarrollo urbano en el Reino Unido, que les permitían llevar a cabo cualquier actividad comercial para los objetivos de la regeneración; v) Las restricciones internas de los servicios del Estado (ministerios y otros), que impiden la creación de entes (sociedades u otros) que podrían agilizar la ejecución de proyectos urbanos complejos; y vi) La ley que impide a las Municipalidades crear y formar parte de corporaciones de desarrollo urbano.

24 La mayoría de las instalaciones industriales y equipamientos que eran propiedad de la Empresa Nacional del Carbón (Enacar) fueron traspasados a instituciones estatales: la Corporación de Fomento (Corfo) o los m unicipios de Lota y Coronel. 


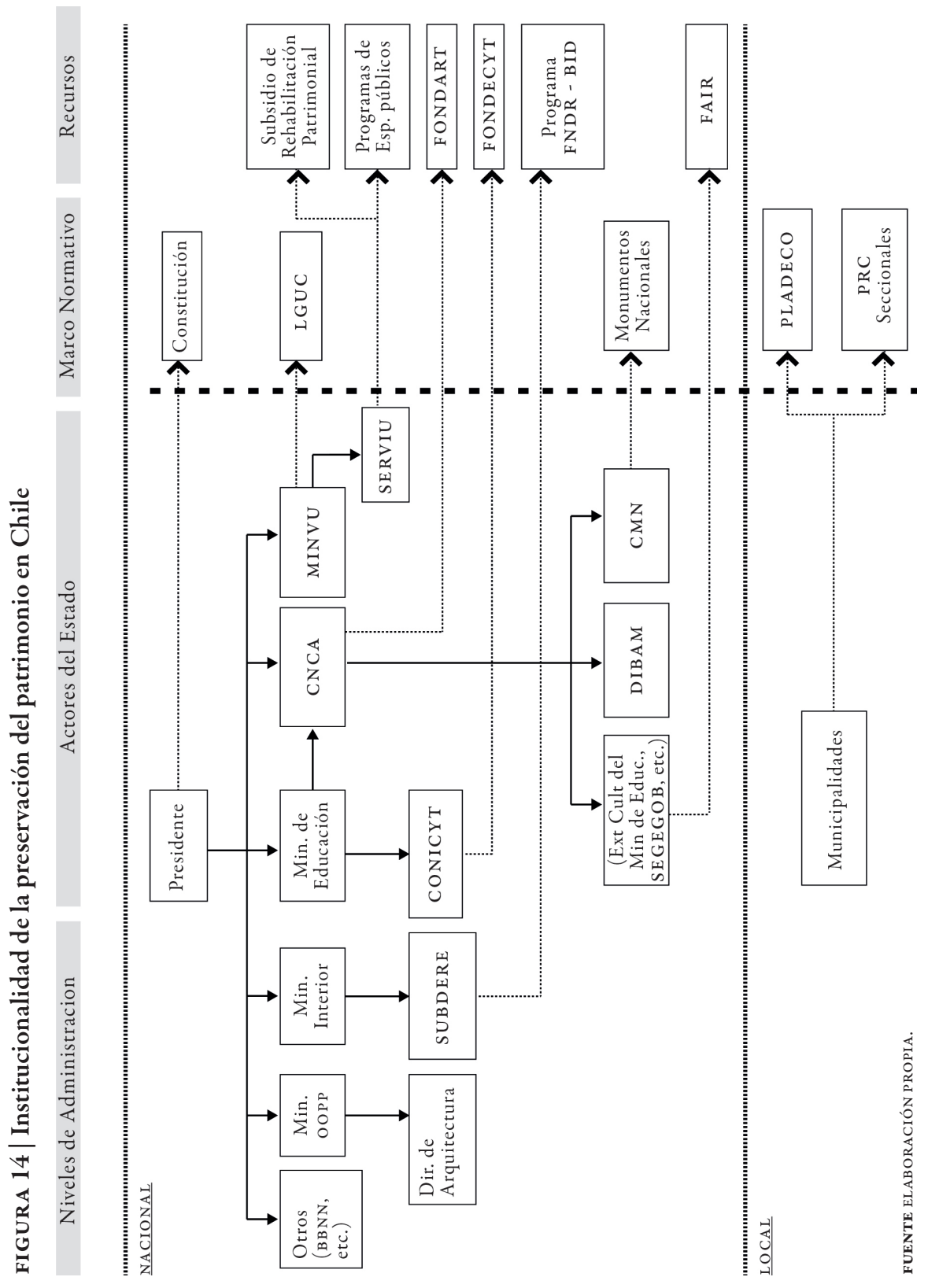




\section{Conclusiones}

Respecto de la primera interrogante señalada en la introducción, sobre qué entenderemos por "parque" o "museo minero", la aplicación de la metodología en el caso del Reino Unido permitió diferenciar tres tipos de actuaciones, las que hemos denominado territorios minero-industriales reconvertidos; exyacimientos reutilizados museísticamente; y parques mineros recreados. El primer y segundo tipo efectivamente implican la reocupación de exáreas minero-industriales. Se diferencian sustancialmente del tercer tipo, cuya propuesta turístico-patrimonial se desarrolla en un sitio minero diseñado ad hoc. En ese sentido, el "parque minero recreado" puede ser descrito como una reutilización del legado construido y la presentación de su legado intangible asociado como un sitio que "recrea" un paisaje minero. Este tipo es sin duda el más cuestionable en términos de su autenticidad. El primer tipo -territorios minero-industriales reconvertidos- distingue aquellas actuaciones que implican una reocupación integral del exterritorio minero. Es decir, que involucran tanto el paisaje como la cultura minera que lo sustenta. Este tipo de actuaciones comprende tanto las instalaciones minero-industriales como los edificios y espacios más domésticos de la comunidad. El segundo tipo, en cambio -exyacimientos reutilizados museísticamente-, se limita a reutilizar las instalaciones minero-industriales y a presentar el mundo del trabajo minero, dejando fuera de la actuación los aspectos sociales y culturales de este legado. Desde la perspectiva de los indicadores de sostenibilidad señalados, el tipo de actuación con mayor potencial de rentabilidad, en términos ambientales, sociales y económicos, es el primero.

Según las posibilidades de éxito de este tipo de reutilizaciones, dos aspectos emergen del análisis. Por una parte, la importancia del factor de localización del exterritorio minero y la distinción entre el exterritorio minero que ha permanecido poblado, y aquellos enclaves que han sido desocupados (por motivos ambientales, de aislamiento, o simplemente por voluntad de la empresa minera, entre los motivos más frecuentes). En Lota y Coronel, la posibilidad de impulsar un desarrollo turístico patrimonial se ve firmemente potenciada por su condición de territorio poblado, así como por su natural asociación al Área Metropolitana de Concepción - esto es, a la situación de la capital regional como plataforma de negocios y de servicios- $\mathrm{y}$ al potencial del sistema portuario como futura puerta de acceso del turismo internacional. Los resultados sugieren que los territorios que han permanecido poblados son los que encuentran más apoyo en los instrumentos de planificación, ya que la recuperación del legado minero contribuye a lograr objetivos de desarrollo social y económico. En contraposición, el apoyo que puedan recibir excampamentos mineros desocupados se ve restringido al ámbito de los instrumentos de preservación del patrimonio. Esta situación favorable es evidentemente una circunstancia que podría no repetirse en otras exáreas mineras. Resulta, pues, un factor casuístico. ${ }^{25}$ Aun más, el discurso de los instrumentos de planificación, así como el análisis

25 Claramente no es el caso de la mayor parte de las exoficinas salitreras en el Norte de Chile, o el asentamiento de montaña de Sewell. 
de los casos internacionales, y la lógica, permiten deducir que un excampamento minero despoblado y alejado debería modificar radicalmente la propuesta -y quizás incluso las expectativas- de un desarrollo turístico patrimonial económicamente significativo.

Por otra parte, los resultados también sugieren que, debido a la magnitud del decaimiento económico de los antiguos territorios mineros de la zona, no es factible esperar que este tipo de reocupaciones se constituya en el motor de la reactivación. De ahí que su rol es más bien el de contribuir de manera relevante a su diversificación económica, con un énfasis identitario, produciendo un espacio de convergencia de diversos actores, recursos y herramientas para una gestión patrimonial, ambiental, social y económicamente sostenible. En este sentido, la reutilización resulta un elemento clave para la sostenibilidad de un plan integral de reconversión.

Respecto del proceso de reconversión llevado a cabo en Lota y Coronel entre 1997 y 2009, los resultados señalan, entre otras, las siguientes debilidades.

En primer lugar, deficiencias en los plazos y la entidad a cargo de liderar la reactivación integral del área. ${ }^{26} \mathrm{~A}$ partir del cierre de la mina el año 1997, la Corfo tuvo un papel muy relevante en el diseño e implementación del Plan Integral de Reconversión. Sin embargo, apenas tres o cuatro años más tarde, su rol ha ido en franca declinación. ${ }^{27}$ Adicionalmente, en los albores del proceso entregó la administración de importantes recursos patrimoniales a una entidad exógena (la Fundación Chile) no validada localmente. Esta falta de validación fue un factor de conflicto con la administración municipal 2004-2008, y de descontento desde otros sectores de la comunidad local, lo que entrabó las posibilidades de trabajo asociativo entre actores. $^{28}$

En segundo lugar, un enfoque disgregado o no sistémico de la reutilización del patrimonio. Es así como la excesiva focalización de las actuaciones en Lota Alto ha descuidado una visión más sistémica de la comuna, y de esta en conjunto con las áreas patrimoniales de Coronel. Entre las evidencias de falta de asociación entre ambas comunas puede contarse la competencia por la ubicación del puerto y la del centro de salud regional. ${ }^{29}$ Concretamente, una política conjunta entre ambas comunas debería apuntar a fortalecer las conexiones del área patrimonial minera con la centralidad de servicios y negocios del Área Metropolitana de Concepción.

En tercer lugar, han existido importantes retrasos en la aplicación de los instrumentos estatutarios de protección del patrimonio. Es así como, a más de catorce

26 Un precedente de procesos de reactivación urbana en Chile, liderados por entidades creadas ad hoc, es el caso de Ribera Norte (López, 2010, p. 488).

27 Algunas señales de esta declinación son la inexistencia de un plan de seguimiento de los logros de la reconversión en el mediano plazo (el último estudio data de 1998); y que actualmente la vinculación con el área se limite a mantener la propiedad de los activos que le fueron traspasados por la Enacar, subsidiar la administración del circuito turístico de la Fundación Chile y continuar -como parte de sus labores habituales de fomento- con programas especiales para el fomento a la inversión en la exzona minera.

28 El municipio reclamaba que los ingresos del circuito no le aportaban ganancias a la comuna, puesto que la Fundación tributaba en Santiago. En esa línea, mantuvo una posición de abierta disputa por la propiedad de los sitios patrimoniales.

29 Competencia en ambos casos "ganada" por Coronel y "perdida" por Lota que, en el caso del centro de salud, aspiraba a que le sirviera para recuperar y reutilizar el antiguo hospital de la empresa carbonífera (Enacar). 
años desde el cierre de las minas, ninguna de las dos comunas cuenta con un plan regulador aprobado que defina áreas o inmuebles de conservación. En Lota Alto esto ha permitido graves afectaciones a la integridad de los pabellones mineros, así como la ocupación del área inmediata al Pique Grande con vivienda social, circunstancia que ha desdibujado su condición de hito del paisaje.

En cuarto lugar, tanto en Lota como en Coronel el plan integral no abordó adecuadamente la mitigación de los diversos riesgos derivados de la actividad minera, problema relacionado con la inexistencia hasta el año 2011 de una ley de cierre de faenas que impulsara la remediación del exterritorio minero.

Finalmente, la principal contribución metodológica del artículo es la utilización de la teoría de sistemas para la construcción de un modelo conceptual que posibilite el análisis comparativo de los casos. Esto resulta relevante tratándose de fenómenos complejos que comprenden dimensiones de carácter tanto espacial como programático y de gestión territorial. Futuras líneas de investigación podrían enfocarse en tres ámbitos:

a. Profundizar en el análisis de experiencias en reutilizaciones de exáreas mineras. Resulta particularmente interesante el estudio de casos de reutilización en Alemania, país con un número de casos similar al Reino Unido, pero con diferencias de enfoque que sería interesante contrastar con el caso anglosajón. Específicamente, por ejemplo, contrastar el enfoque marcadamente historicista en el Reino Unido con el enfoque más abierto a intervenciones contemporáneas del caso alemán.

b. Explorar las proyecciones de este enfoque en el contexto de otros países latinoamericanos a la luz de las particularidades territoriales de la actividad minera en dichos países, así como del marco normativo, institucional y social del desarrollo urbano y de la protección del patrimonio.

c. Profundizar en el contexto chileno sobre posibles ajustes que requeriría el marco institucional para impulsar la reutilización de las ex instalaciones en la fase posminera. Dentro de esta línea, el énfasis sería la articulación de los marcos normativos de la planificación urbana y la protección de patrimonio, con la legislación ambiental y las leyes mineras. Esto sería particularmente relevante para explorar el diseño de políticas que aseguren que las compañías mineras asuman un rol más preponderante en la remediación ambiental durante la fase posextractiva y en el traspaso de los activos, entre otros. @EURE 


\section{Referencias bibliográficas}

Aburto, H. \& Gutiérrez, M. (1999-2000). Coronel: historia y sociedad carbonífera. Revista de Historia, 9-10(1-2), 111-122. Disponible en http://bit.ly/11hyB9V

Alcina, J. (1994). Aprender a investigar: métodos de trabajo para la redacción de tesis doctorales (bumanidades y ciencias sociales). Madrid: Compañía Literaria.

Aravena, J. \& Betancur, C. (1995). Reconversión laboral del carbón. Tesis de Grado de Literatura en Sociología, Universidad Arcis, Santiago.

Cáceres, G. (2001). El territorio en Chile: tempranos aportes desde el urbanismo. En F. Arenas \& G. Cáceres, Ordenamiento del territorio en Chile. Desafíos y urgencias para el tercer milenio (pp. 119-124). Santiago: Ediciones Universidad Católica de Chile.

Carvajal, D. \& González, A. (2003a). La contribución del patrimonio geológico y minero al desarrollo sostenible. En G. Villas Bôas, G. de Albuquerque \& A. González (Eds.), Patrimonio geológico y minero en el contexto del cierre de minas (pp. 27-49). Rio de Janeiro: Centro de Tecnologia Mineral (CETEM), Ministério da Ciência e Tecnologia, Coordenação de Desenvolvimento Sustentável. Disponible en http://www.cetem.gov.br/publicacao/CTs/ CT2003-128-00.pdf

Carvajal, D. \& González, A. (2003b). El papel de los parques y museos mineros en el desarrollo sostenible. De re metallica (Madrid), Revista de la Sociedad Española para la Defensa del Patrimonio Geológico y Minero, 1 (2a época), 26-36. Disponible en http://www.sedpgym.es/ descargas/Metallica/n1_26.pdf

Casanelles, E. (1999). Recuperación y uso del patrimonio industrial. Ábaco. Revista de Cultura y Ciencias Sociales, 19, 11-18. URL estable: http://www.jstor.org/stable/20796398

Castillo Ruiz, J. (2003). La protección del patrimonio inmueble en la normativa internacional: la contextualización como máxima tutelar. En Instituto Andaluz del Patrimonio Histórico, Repertorio de textos internacionales del patrimonio cultural (pp. 64-71). Granada: Comares.

Cociña, C., Klenner, M., Lira, I., Sellés, J. I. \& Valenzuela, N. (2006). Proyecto Ribera Norte. Trabajo presentado para el Curso Ciencias de la Tierra y Medioambientales (CTMA) II de la Escuela de Arquitectura de la Pontificia Universidad Católica. Disponible en http://bit. ly/19IrgYM

Cole, D. (2004). Exploring the sustainability of mining heritage tourism. Journal of Sustainable Tourism, 12(6), 480-494. doi: 10.1080/09669580408667250

Garcés, E. (1999). Las ciudades del salitre: un estudio de las oficinas salitreras en la región de Antofagasta. $2^{\mathrm{a}}$ ed. Santiago: Orígenes.

Garcés, E., Cooper, M. \& Baros, M. (2007). Las ciudades del cobre: Sewell, Chuquicamata, Potrerillos, El Salvador, San Lorenzo, Pabellón del Inca y Los Pelambres. Santiago: Ediciones Universidad Católica de Chile.

Hernández Pavón, E. (2003). El patrimonio cultural como recurso económico: la doctrina internacional. En Instituto Andaluz del Patrimonio Histórico, Repertorio de textos internacionales del patrimonio cultural (pp. 72-95). Granada: Comares.

Hill, J. N. \& Evans, R. K. (1972). A model for classification and typology. En D. L. Clarke (Ed.), Models in Archaeology (pp. 231-276). Londres: Methuen. 
Hospers, G-J (2002). Industrial heritage tourism and regional restructuring in the European Union. European Planning Studies, 10(3), 397-404. doi: 10.1080/09654310220121112

Jonsen-Verbeke, M. (1999). Industrial heritage: a nexus for sustainable tourism development. Tourist Geographies, 1(1), 70-85. doi: 10.1080/14616689908721295

Leary T. \& Sholes E. (2000). Authenticity of place and voice: Examples of industrial heritage preservation and interpretation in the US and Europe. The Public Historian, 22(3), 49-66. URL estable: http://www.jstor.org/stable/3379578

López, M. I. (2010). Proyecciones del patrimonio cultural minero en Chile. La reocupación cultural y turistica como estrategia de revitalización: el caso del territorio minero del Golfo de Arauco. Tesis Doctoral, Escuela Técnica Superior de Arquitectura de Madrid (ETSAM), Universidad Politécnica de Madrid, España.

Martinic, M. (2004). La minería del carbón en Magallanes entre 1868-2003. Historia, 37(1), 129-167. http://dx.doi.org/10.4067/S0717-71942004000100005

Martinic, M. (2010). El carbón en Magallanes: historia y futuro. Punta Arenas: Minera Isla Riesco/ Municipalidad de Río Verde.

Mazzei, L. (1997). Los británicos y el carbón en Chile. Atenea, Revista de Ciencia, Arte y Literatura, 475, 137-167. Disponible en http://bit.ly/13leJa0

Muñoz, M. D. (2000). Ciudad y memoria, el patrimonio industrial en Lota, Coronel, Tomé y Lebu. Concepción: Universidad del Biobío.

Muñoz, M. D. \& Sanhueza, R. (2006). Importancia y significado del patrimonio industrial minero en la construcción de la identidad. Congreso Internacional Puesta en Valor del Patrimonio Industrial - Sitios, Museo y Casos. Santiago de Chile, 21 al 23 de marzo.

Orche, E. (2002a). Puesta en valor del patrimonio minero. Aplicación al caso de las minas de Fontao (Pontevedra). Curso de verano "Defensa del patrimonio geológico y minero". Universidad Internacional de Andalucía, La Rábida (Huelva).

Orche, E. (2002b). Parques mineros, desarrollo sostenible y ordenación del territorio. Simposio sobre Recursos Mineros y Ordenación del territorio. Programa Iberoamericano de Ciencia y Tecnología para el Desarrollo. (CYTED), Universidad de Moa, Cuba.

Orche, E. (2003). Puesta en valor del patrimonio geológico-minero: el proceso de adaptación de explotaciones mineras a parques temáticos. En G. Villas Bôas, G. de Albuquerque \& A. González (Eds.), Patrimonio geológico y minero en el contexto del cierre de minas (pp. 51-68). Río de Janeiro: Centro de Tecnologia Mineral (CETEM), Ministério da Ciência e Tecnologia, Coordenação de Desenvolvimento Sustentável.

Orche, E. (2004). La función multidisciplinar de los parques geomineros. Actas de la V Reunión Nacional de la Comisión de Patrimonio Geológico de la Sociedad Geológica de España. Molina de Segura, mayo de 2001, Universidad de Murcia (España).

Ortega, L. (1992). La frontera carbonífera 1840-1900. Mapocho, 31(Primer semestre), 131-148. Disponible en http://bit.ly/17oEN8A

Pérez, L. (2008a). El barrio Puchoco en Schwager. Cuando la industria construye el paisaje cultural. Urbano, 11(18), 47-58. Disponible en http://www.revistaurbano.cl/index.php/urbano/ article/view/120 